\title{
Modeling of the Optimization Procedure for Selecting the Location of New Thermal Power Plants (TPP)
}

\author{
Zdravko Milovanović \\ Department of Hydro and Thermal Engineering, University of Banja Luka, \\ Faculty of Mechanical Engineering, Stepe Stepaniovića 71, Banja Luka, B\&H. \\ Corresponding author: zdravko.milovanovic@ mf.unibl.org \\ Snježana Milovanović \\ Department of Materials and Structures, University of Banja Luka, Faculty of Architecture, \\ Civil Engineering and Geodesy, Banja Luka, Stepe Stepanovića 77/3, B\&H. \\ E-mail: snjezana.milovanovic@aggf.unibl.org \\ Valentina Janičić Milovanović \\ Independent Researcher, \\ Solunska 8a, Banja Luka, B\&H. \\ E-mail: valentina.mil@live.com

\section{Svetlana Dumonjić-Milovanović \\ Partner Engineering Ltd., Banja Luka, Kralja Nikole 25, Banja Luka, B\&H. \\ E-mail: svetlanadm@ymail.com}

\section{Dejan Branković} \\ Department of Hydro and Thermal Engineering, University of Banja Luka, \\ Faculty of Mechanical Engineering, Stepe Stepaniovića 71, Banja Luka, B\&H. \\ E-mail: dejan.brankovic11@gmail.com
}

(Received December 28, 2019; Accepted March, 9, 2020)

\begin{abstract}
At the level of design of thermal power plants (TPP), when making decisions related to the choice of its macro location and micro location, disposition solution and equipment structure, the choice of the right decision method is of particular importance. Multi criteria analysis involves solving inadequately structured problems, while in practical terms it is a necessary tool in solving the day-to-day tasks of decision-making, management actions, both at the design level and the exploitation of complex energy and process systems. The development of new methods and the improvement of existing multi criteria analysis methods have influenced their increasing application in the field of energy, from both theoretical and practical aspects. A particular segment of the application of multi criteria analysis methods is to make strategic or operational decisions when solving multidisciplinary problems with predominantly technical or predominantly economic content, whether looking at a part or the energy system as a whole. The application of these methods in choosing the right solutions in the decision-making tasks of management in the design, maintenance and operation of thermal power plants is based on the development of information technology and computer technology. There are several methods in use today, of which the following should be emphasized: PROMETHEE (Preference Ranking Organization METHod of Enrichment Evaluation), AHP (Analytic Hierarchy Process), IKOR, ELECTRE (ELimination Et Choice Translating REality), MAX-MIN, MAX-MAX, Hurwicz (combination of max-max and max-min methods), SAW (Simple Additive Weighting Method), TOPSIS (Technique for Order Preference by Similarity to Ideal Solution), conjunctive method, disjunctive method, etc. Depending on the method used, the ranking of alternatives or criteria, the best alternative or criterion or set of alternatives or criteria that meet certain conditions is obtained as a solution. Problems that can be considered using multi-criteria decision-making have certain common characteristics: a large number of criteria that must be created by the decision maker, a high likelihood of conflict between the criteria, inseparable (different) units of measure (as a rule, each criterion has different units of measure), as well as design or the choice of optimal concepts in a
\end{abstract}


International Journal of Mathematical, Engineering and Management Sciences

Vol. 6, No. 1, 118-165, 2021

https://doi.org/10.33889/IJMEMS.2021.6.1.009

predetermined space. Solutions are either designing the best alternative or choosing the best action from a set of predefined final actions. This paper provides a brief description of the more important methods, along with an analysis of their advantages and disadvantages, as well as the possibility of applying them to solve the specific problem of choosing a micro location for TPP. Starting from the application of the modified multi criteria method for determining the priorities between individual alternatives for ranking and selecting the optimal micro location within a certain macro location within a predetermined framework, in a decision situation involving a number of decision makers of different specialty, examples of micro location selection for new thermal power facilities of TPP Stanari are given, TPP Gacko 2 and TPP Ugljevik 3, with preliminary definition of elimination criteria and criteria for comparison of locations of given TPPs.

Keywords- Multi criteria decision making, Analytical hierarchical process, Choice of micro location, Criteria, Thermal power plant (TPP).

\section{Introduction}

The thermal power plants (TPP) design and construction process includes a number of activities, ranging from the preparatory and exploration phase related to the location (design substrates), location conditions analysis (substrate analysis), through coal reserves and quality to the design, construction and installation phase, commissioning labor and commercial exploitation. Prior to that, the TPP needs to be covered by an appropriate regulatory plan (potential candidate), whereby the natural fuel resource itself (coal, gas, biomass, etc.) identifies individual macro-locations as alternative construction solutions. Usually, the list of candidates for construction is determined on the basis of medium and long-term plans for the construction of energy facilities (energy sector development strategy), which are based on electricity balances, with pronounced prospective consumer needs in relation to electricity and heat supply, as well as technological steam. TPP design is preceded by a series of preparatory activities, which include the preparation of appropriate documentation (Preliminary or Study on the economic feasibility of construction) and the carrying out of certain preliminary study and research works (raw material base, natural characteristics of potential sites, local legislation, etc.), on the basis of which can achieve optimal decisions regarding the use of natural resources, obtain a concession contract, determine the concession fee, and evaluate the economic and financial indicators of the future TPP. Choosing the right location for TPP, in addition to creating the preconditions for greater investment savings and better business effects during their exploitation, contributes to the safety and reliability of their operation, as well as increased efficiency against the possible risks on the other hand. The selection of locations for installations with increased safety and security requirements in some countries is also regulated by certain regulations (IAEA Safety Standards Series, YUS standards, Bishnoi and Basu, 2005). Unlike in Croatia, there are no such regulations in B\&H and Serbia, which further complicates the choice itself. In doing so, each facility must meet environmental criteria with respect to the permissible emissions of pollutants, with priority being given to sites that do not conflict with nature protection and areas valuable for tourism and recreation.

Technical and technological development requires continuous review of existing criteria for the selection of potential areas and construction of thermal power facilities. From the aspect of space occupation and spatial development, special criteria relate to the preservation of the value of space for priority activities of the area, the possible use of more environmentally friendly energy (gas), avoiding the additional burden of already burdened space, primarily eliminating conflicts and harmonization with the interests of protection of natural heritage, with the necessary valorization of landscape features and relevant environmental components. In doing so, devastated areas and spaces with no other activities, which would be rehabilitated by the construction of a thermal power plant, with retained employment and economic dynamics of depopulation areas, have the advantage 
International Journal of Mathematical, Engineering and Management Sciences

Vol. 6, No. 1, 118-165, 2021

https://doi.org/10.33889/IJMEMS.2021.6.1.009

of location. The final choice should take into account the particular sensitivity and lack of energy in the micro and macro areas, as well as the wider energy community of Southeast Europe. The importance of site selection for energy facilities has two aspects of observation. The first aspect covers the impact of macro and micro locations on the TPPs under consideration (the effect of seismic, hydrology, geology, meteorology, etc.), and the second the impact of the TPP on the narrower and wider area both in normal exploitation and in incident situations (impact on the biosphere, impact on thermal pollution, impact on radioactive pollution, impact on human health, impact on flora and fauna, etc.).

The application of a multi criteria analysis model to solve problems with a number of alternative solutions requires that all possible solutions to a given problem be defined beforehand. In doing so, all parameters for multi criteria analysis must be pre-defined (multiple criteria, conflicts of criteria, unmatched units of criteria measures, choice of the best alternative or solution, or ranking of alternatives). The first step in problem solving is to define the very criteria for a comprehensive characterization of a given problem, which are also a measure of the characteristics of the system to be optimized, in order to meet predefined goals. The evaluation and selection of sites for energy facilities and installations is performed on the basis of safety, technical, technological, economicfinancial, social, cultural and similar aspects, which contain defined elimination and comparison criteria for location selection, (Milovanović et al., 2011a and 2011b). Alternative solutions to the problem are alternatives or variants of solutions, which will be compared and ranked. Each criterion is assigned a weighting coefficient, which reflects its importance from the perspective of the decision maker. The so-called "goal analysis", most often given in the form of specification and analysis of the goals that should be achieved by solving the problem, is of great help in defining the criteria. As in practice we often encounter conflicts of goals at the strategic level, which is directly transmitted to the conflict of dominant criteria, it is possible to determine the optimal solution to a given problem by using multi criteria analysis methods.

\section{Overview of the Following Research}

Multi criteria analysis is used to understand the various decision-making mechanisms and decisionmaking problems, in case qualitative and quantitative evaluations have been given previously for making the choices themselves. In addition to this term, the literature uses the terms vector optimization and multi criteria optimization to express the same content. The term Pareto optimality was introduced into operational research in 1951 in the pioneering work of Koopmans (1951), while the work of Kuhn and Tucker (1951) considered a more general approach in the form of solving the problem of maximization of a vector function over a finite set of constraints. All known method classifications are essentially different because they start from a different set of methods and different classification criteria. A review of the available literature reveals the dominance of several groups of multi criteria analysis methods: the ELECTRA method group, by Roy (1976), the Analytic Hierarchy Processing (AHP) method group, by Saaty (1980), and the PROMETHEE method group authored by Brans and Vincke (1985). Regarding the application of multi criteria methodology to the location of TPP, significant work is related to professor (Panigrahi, 2014; Swain, 2014) from the National Institute of Technology Rourkela, India (Fuzzy-TOPSIS location selection methodology for the thermal power plant). According to the methodology presented, the first step involves the selection of 21 criteria for selecting the location of the TPP, while the second step involves describing the evaluation of each of the criteria, as well as making a decision for each of the criteria by the respective expert. An alternative evaluation for each of the criteria is given in tabular form, with a view using the Fuzzy approach. Then, Fuzzy TOPSIS is linked to a total of ranked criteria and alternatives, to obtain a total score for choosing a TPP location. The best result 
International Journal of Mathematical, Engineering and Management Sciences

Vol. 6, No. 1, 118-165, 2021

https://doi.org/10.33889/IJMEMS.2021.6.1.009

is selected as the most favorable location for TPP. Less formal environmental management tools include, but are not limited to, the Life Cycle Assessment (LCA) standardized by the international standards ISO 14040 and ISO 14044 (Lee and Inaba, 2004; Weidema et al., 2018). As ISO standards do not provide guidance for the implementation of the optional weighting process factors in LCA, there is a close analogy between life cycle assessment and decision-making tools (Chevalier and Rousseaux, 1999) such as multi criteria analysis, and LCA can be understood as a decision problem (Hertwich and Hammitt, 2001a and 2001b). A multi-criteria approach to problem solving in the design of an LCA study can be used in all four stages of the LCA (Seppälä, 2003). Grouping in the LCA phase to calculate the resulting indicators can be performed using MAUT (Multi Attribute Utility Theory - MAUT) technology. Multi-criteria decision-making methods are also used to categorize the impact at the level of certain technological points in electricity production at the level of a hierarchically higher power system. In structuring problems for multicriteria decision-making, the so-called "Value tree", on the basis of which it is easier to select influential categories and classify them (Seppälä, 2003). Also, this analysis is also used to rank alternative energy sources or to compare energy technologies with respect to their environmental impact, whereby weighting factors of different criteria are determined on the basis of weighting factors. Thus, Hobbs and Meier (2000) applied this method to evaluate a number of hypothetical development plans using 12 criteria (USD costs / year, increase $\%, \mathrm{CO}_{2}$ emissions $\mathrm{t} /$ year, $\mathrm{SO}_{2}$ emissions $\mathrm{t} /$ year, $\mathrm{NO}_{2}$ emissions $\mathrm{t} /$ year, index visibility $\%$, change in the use of water $\mathrm{m}^{3} / \mathrm{s}$, change in the amount of solid waste $\mathrm{t} /$ year, use of remote locations of MW installed capacity, the existence of new HP projects of MW installed capacity and system reliability - expected undelivered $\mathrm{kWh} /$ year).

\section{Description of the Procedure of Selecting a New Tap Location at the Design Stage}

Deciding on a location for future TPPs is one of the most important business decisions related to the entire process that follows the earliest stages of their life cycle - preparation for design, design and construction process, up to commissioning and their trial run. In the process of valorization and selection of acceptable potential micro-locations for TPP within the selected macro-location, it is necessary to apply a certain procedure, which will be uniform in all its aspects. In order to achieve this goal, it is necessary to define general criteria for the selection and comparison of selected micro locations within the previously established macro location using the multi-criteria optimization method. The process of making a location decision is narrowly determined by making other decisions, of which the importance of defining the purpose of TPP (production of only electrical or electrical and thermal energy) and the choice of raw material base at TPP are particularly important. An algorithm for the location selection procedure is given in Figure 1. Accessing a more serious project assignment and required (legally required) project documentation requires a predefined input database. Possible additional backgrounds, other project and other documentation, as well as other information relevant for the preparation of further project documentation are defined after preliminary analyzes have been completed and during the process of gradual preparation of documentation (the lower level of project documentation determines the scope and content of the investigative actions required for the next higher level documentation). The level of development on which the multi criteria analysis methods are located allows them to be used without any major problems to solve the real problems of choosing variant micro location solutions for a particular thermal power plant. In the selection and evaluation of conceptual variant solutions in the process of comparison and selection of the optimal TPP micro location within the selected macro location, the most commonly used the following criteria and conditions: space required for accommodation of thermal power block facilities and facilities (Figure 2), occupancy of micro location by industrial or other facilities, topographic conditions, seismological and engineering-geological characteristics 
International Journal of Mathematical, Engineering and Management Sciences

Vol. 6, No. 1, 118-165, 2021

https://doi.org/10.33889/IJMEMS.2021.6.1.009

of soil, conditions for transport and delivery of plants and equipment, conditions for waste shipment and deposition, transport conditions and shipment of coal, conditions for shipment and deposition of ash and slag, conditions and possibilities of water supply, conditions and method of connection to the electricity grid, conditions and method of connection with public roads, environmental conditions, economic conditions, social justification, population and development, reliability, maintenance and risk assessment, electricity placement, as well as other conditions, including possibly other conditions or criteria not covered by the previously specified ones, which may be relevant for the considered micro location within the macro location (radioactive areas, areas treated by special legislation).

According to the national legislation, the premises that are the subject of special investor attention, the planned reserved area within the already built plants such as TPP Gacko and TPP Ugljevik, etc.). Macro location for each of the coal mines from the observed region is defined by specific strategic documents at the republic or local level. Sometimes these solutions are very expensive and do not follow the trend of development of new technologies and use of new equipment in the field of thermal power engineering, so it is necessary to additionally evaluate variant solutions according to certain criteria and conditions, which will be applied in the process of comparison and selection of selected micro locations for TPP implementation in within a pre-selected macro location.

These criteria, apart from their differences, can be mutually contradictory, so in order to evaluate alternatives in multi criteria analysis, it is necessary to have a method to enable their simultaneous processing, taking into account the inherent capabilities of each technological approach and their relative mutual relevance to the criteria. The process of engineering optimization is a systematic search for the optimal solution to a given engineering problem, taking into account the defined optimality criteria, and in the conditions of satisfying the set constraints. The assumption is, of course, that the problem has a sufficient "excess" of internal degrees of freedom (those that can be decided by the designer, as they are not determined by the physical laws of the problem), which become variables of the optimization process.

In the event that some of the substrates are unavailable, the investor and the designer jointly evaluate the impact of the unavailability of the substrate on the expected results and the dynamics of documentation preparation, the risk and the way to overcome the problem. The choice of location of a thermal power plant depends primarily on the supply and available quantities of fuel and water, while the choice of location of a power plant or sub-station is subordinated primarily to the consumers to be supplied with thermal energy.

Phase 1 determines the elimination criteria for location selection, resulting from legal legislation, the application of domestic and international practice, and the technical and technological requirements of the energy facility itself, and valorizes the wider area, rejecting areas that are unacceptable by at least one elimination criterion. The main objective of this phase is to eliminate as much of the area of interest as possible and to simplify the process of searching for and evaluating potential micro-locations within a wider macro-location. In case at the stage of development and design there are not enough good quality and reliable data for the application of the elimination criteria for the selection of micro locations, they are not used, with the obligation of their realization after additional field studies have been carried out. The aim is to prevent the irreversible rejection of potentially good, but not sufficiently explored, locations, while the possible passage of "bad" locations into the next phase of the research will surely be "discovered" and "sanctioned" in further 
stages of the site selection process using multi-criteria decision-making methods. Table 1 provides an overview of the elimination criteria for the selection of coal and gas TPP locations. Upon realization of this phase, potential locations in the wider area that have not been eliminated are identified, so-called global screening ("Site Screening").

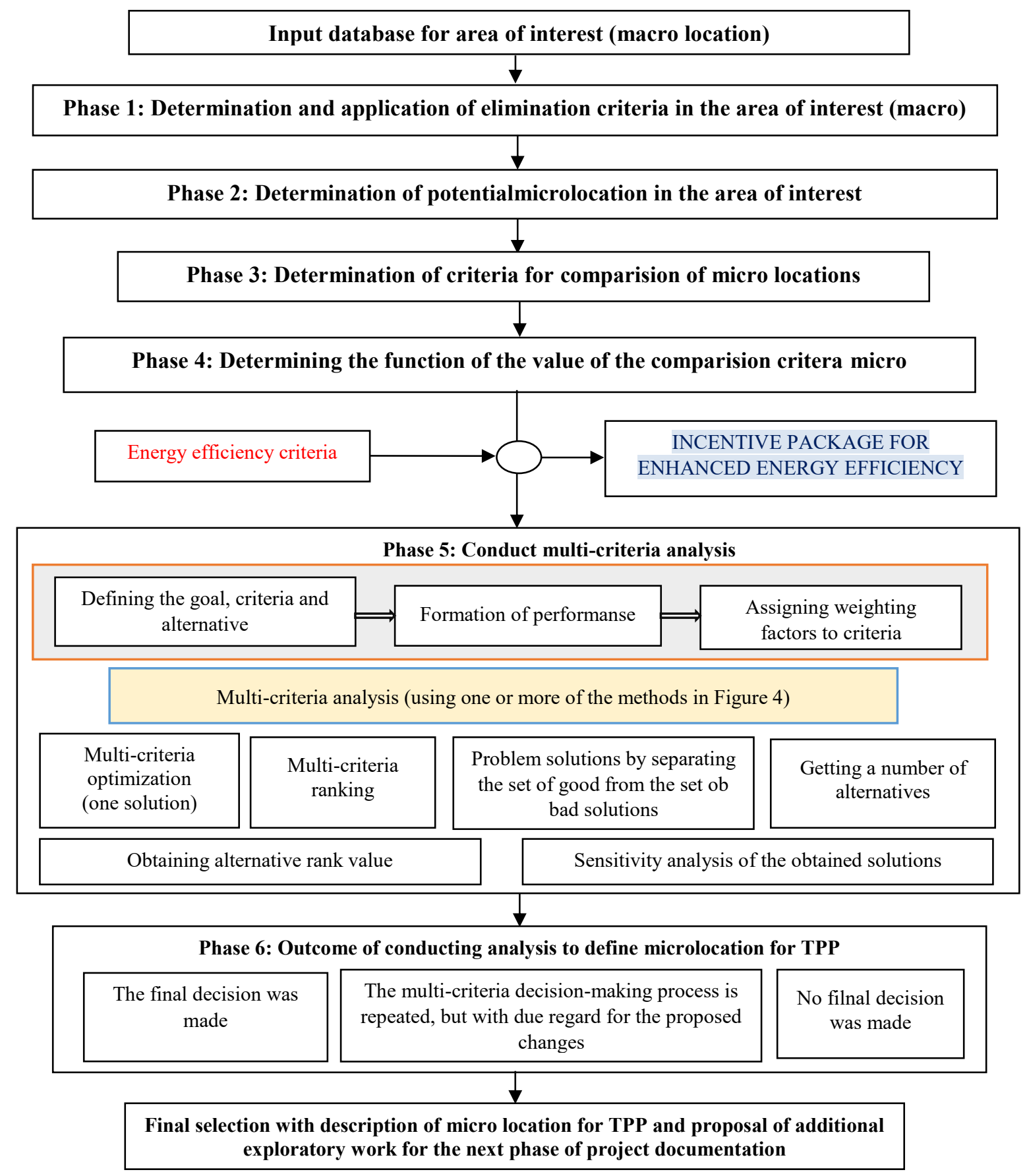

Figure 1. Algorithm for selecting the location of new TPPs. 

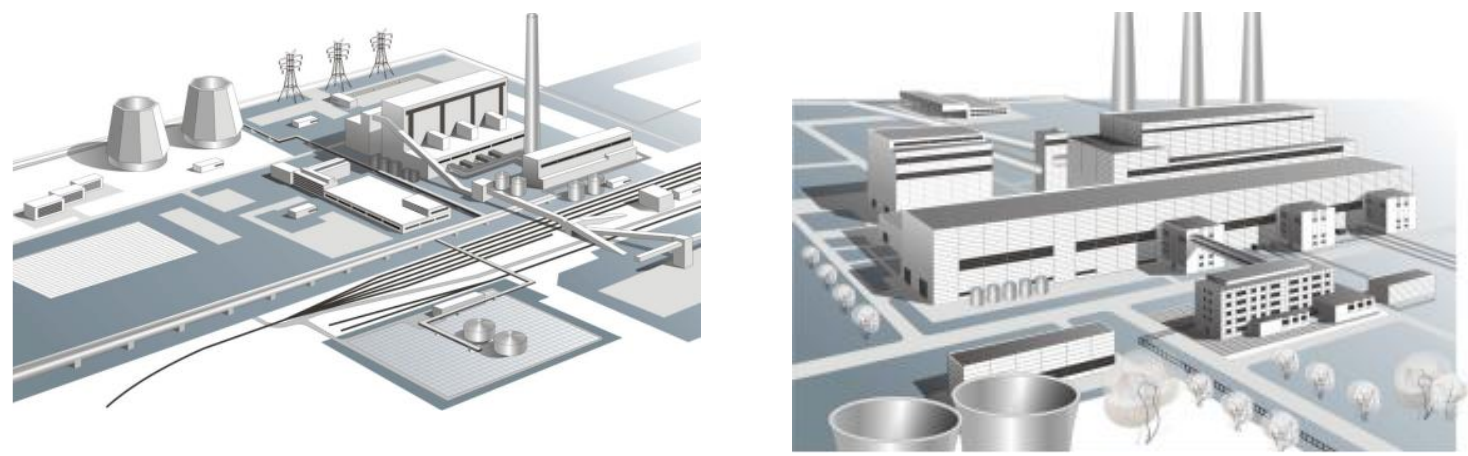

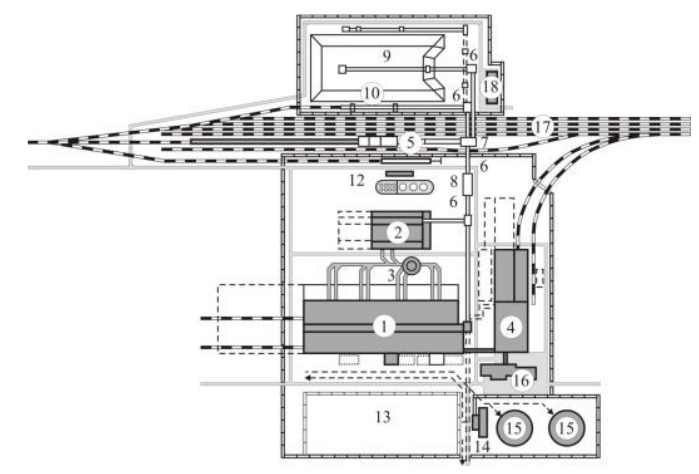

a) coal thermal power plant (TPP)

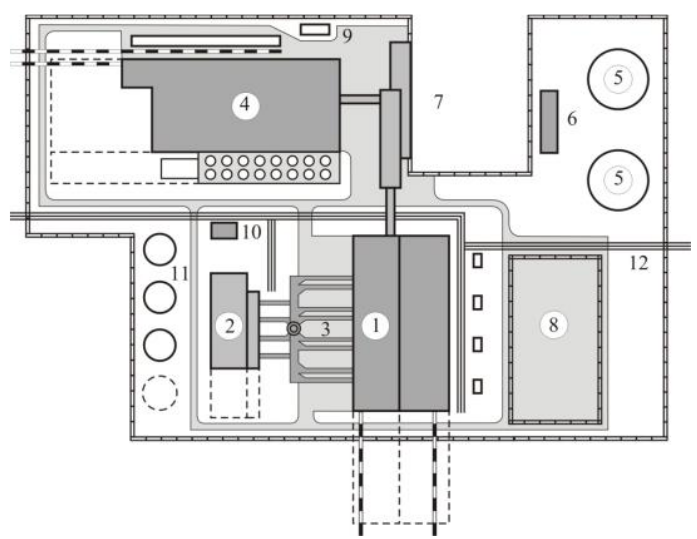

b) gas / fuel oil thermal power plant (TPP)

Legend: 1 - the main building; 2 - boiler room; 3 - chimney; 4 - integrated auxiliary housing; 5- tipper car for a) / cooling towers for b) ; 6 - fuel supply overpass for a) / pumping station for technical water supply for b); 7 - overflow unit for a) / administrative building with a checkpoint for b); 8 - crushing case for a) / outdoor switchgear for b); 9 - coal warehouse for a)/ receivers for b); 10 - railroad unloading overpass for a) / gas distribution point for b); 11 - defrosting device for a)/ hot water storage tanks for b); 12 - oil and oil facilities for a) / heating pipelines for b); 13 - outdoor switchgear; 14 - pumping station for technical water supply; 15 - cooling towers; 16 - administrative and household building with a checkpoint; 17 - TPP railway station; 18 - fuel and transport workshop

Figure 2. General plan view of coal-fired TPP and gas-fired TPP, (Ohlopkova, 2019).

The locations that remain after Phase 2 need to be further evaluated and most often compared, in order to rank them according to the affordability of TPP accommodation locations. The rules for evaluating potential micro-locations, which need to be defined in advance, are benchmarking criteria (BC) and are usually given in the form of a requirement to achieve some goal. The benchmarking criteria are usually grouped, Table 2.

Increasing the level of impact of energy facilities and installations on environmental degradation requires both developed and developing countries to align the needs between consumption requirements and energy production, while improving energy options for sustainable development. By aligning the objectives of protecting air, water, land, flora, fauna and landscape features with socio-economic goals, the primary goal is to maximize the net economic well-being of energy 
International Journal of Mathematical, Engineering and Management Sciences

Vol. 6, No. 1, 118-165, 2021

https://doi.org/10.33889/IJMEMS.2021.6.1.009

development, while maintaining a stock of economic, environmental and socio-cultural values for future generations and providing a network to meet basic needs and protect categories of the poor.

Table 1. Overview of the elimination criteria for the selection of coal / gas / fuel oil TPP locations.

\begin{tabular}{|c|c|c|}
\hline Label & Description & Sub-criteria \\
\hline $\begin{array}{l}\text { Group } \\
\text { EC } 0\end{array}$ & $\begin{array}{l}\text { Compliance with planning } \\
\text { documentation }\end{array}$ & $\begin{array}{l}\text { EC 0.1. Compliance with the spatial planning documentation, } \\
\text { EC 0.2. Consistency with energy sector development strategies, } \\
\text { EC } 0.3 \text {. Consistency with economic policy, etc. }\end{array}$ \\
\hline $\begin{array}{l}\text { Group } \\
\text { EC } 1\end{array}$ & $\begin{array}{l}\text { Space required to house } \\
\text { MPF facilities and ancillary } \\
\text { equipment }\end{array}$ & $\begin{array}{l}\text { EC 1.1. Main propulsion facility (MPF): boiler, turbines, electric generator, } \\
\text { EC 1.2. Auxiliary plants (CWT-chemical water treatment, supply of primary and } \\
\text { auxiliary fuels, shipping by-products from the process of exploitation, ecological } \\
\text { systems - wastewater, ESF, chimney, etc., technical gas system, electrical equipment - } \\
\text { switchgear, transformers, etc.) }\end{array}$ \\
\hline $\begin{array}{l}\text { Group } \\
\text { EC } 2\end{array}$ & $\begin{array}{l}\text { Conflicts with other spatial } \\
\text { content }\end{array}$ & $\begin{array}{l}\text { EC 2.1. Special purpose areas (military facilities and installations), } \\
\text { EC 2.2. Existing and planned population of the area, } \\
\text { EC 2.3. Tourist and recreational areas, } \\
\text { EC 2.4. Airport maneuvering zones, } \\
\text { EC 2.5. Transport infrastructure (roads and railways), } \\
\text { EC 2.6. Protection zones from other industrial and commercial buildings, } \\
\text { EC 2.7. Other (agricultural facilities, water supply systems, etc.) }\end{array}$ \\
\hline $\begin{array}{l}\text { Group } \\
\text { EC } 3\end{array}$ & $\begin{array}{l}\text { Technical and technological } \\
\text { aspects }\end{array}$ & $\begin{array}{l}\text { EC 3.1. Amount and transport of cooling water required, } \\
\text { EC 3.2. Danger of flooding, } \\
\text { EC 3.3. Power aspects of connection to the transmission network, } \\
\text { EC 3.4. Settlements - gas network, } \\
\text { EC 3.5. Settlements - district heating network, } \\
\text { EC 3.6. Settlements - water supply network } \\
\text { EC 3.7. Mining and quarrying }\end{array}$ \\
\hline $\begin{array}{l}\text { Group } \\
\text { EC } 4\end{array}$ & $\begin{array}{l}\text { Economic and financial } \\
\text { aspects of construction and / } \\
\text { or operation and framework } \\
\text { energy efficiency and } \\
\text { sustainability }\end{array}$ & $\begin{array}{l}\text { EC 4.1. Investment costs } \\
\text { EC 4.2. Costs of exploitation (operation) and maintenance, } \\
\text { EC 4.3. Costs of fuel and supplies, } \\
\text { EC 4.4. Costs related to the impact of greenhouse gas emission restrictions, } \\
\text { EC 4.5. Economic life of power plants, } \\
\text { EC 4.6. Economic profitability of investments in power plants, } \\
\text { EC 4.7. Return on energy input (Indicative energy efficiency) }\end{array}$ \\
\hline $\begin{array}{l}\text { Group } \\
\text { EC } 5\end{array}$ & Security aspects and risk & $\begin{array}{l}\text { EC 5.1. Seismotectonics, } \\
\text { EC 5.2. Neotectonics, } \\
\text { EC 5.3. Hydrogeology, } \\
\text { EC 5.5. Lithological and geomorphological characteristics, } \\
\text { EC 5.6. Topography, } \\
\text { EC 5.7. Settlements - density and security aspects of location }\end{array}$ \\
\hline $\begin{array}{l}\text { Group } \\
\text { EC } 6\end{array}$ & $\begin{array}{l}\text { Ecological aspects and } \\
\text { environmental protection in } \\
\text { periods during the life cycle } \\
\text { (construction, operation, } \\
\text { revitalization, reconstruction } \\
\text { and modernization and } \\
\text { removal of facilities) }\end{array}$ & $\begin{array}{l}\text { EC 6.1. Protection of natural heritage, } \\
\text { EC 6.2. Protection of cultural heritage, } \\
\text { EC 6.3. Protection of biological and ecological values, } \\
\text { EC 6.4. Social aspects, } \\
\text { EC 6.5. Sociological values of endangered nature }\end{array}$ \\
\hline
\end{tabular}


International Journal of Mathematical, Engineering and Management Sciences

Vol. 6, No. 1, 118-165, 2021

https://doi.org/10.33889/IJMEMS.2021.6.1.009

Table 2. Comparison criteria for selection of coal / gas / fuel oil TPP locations.

\begin{tabular}{|c|c|c|}
\hline Label & Description & Sub-criteria \\
\hline $\begin{array}{c}\text { Group } \\
\text { PK } 0\end{array}$ & $\begin{array}{l}\text { Spatial } \\
\text { planning } \\
\text { conditions }\end{array}$ & $\begin{array}{l}\text { PK 0.1. The potential for conflict in space with other users of space, } \\
\text { PK 0.2. The relationship of the location to the protected areas of the location in and near the location, } \\
\text { PK 0.3. Purpose and use of space (demography and settlement, agriculture and forestry, industry and } \\
\text { mining, school system and education) }\end{array}$ \\
\hline $\begin{array}{c}\text { Group } \\
\text { PK } 1\end{array}$ & $\begin{array}{l}\text { Geological- } \\
\text { seismological } \\
\text { indicators }\end{array}$ & $\begin{array}{l}\text { PK 1.1. Seismological and seism-tectonic indicators, } \\
\text { PK 1.2. Local geological indicators, } \\
\text { PK 1.3. Hydro geological indicators, } \\
\text { PK 1.4. Hydrological indicators (dispersion of waste heat, dispersion in water, distance of surface } \\
\text { flows from landfill, etc.), } \\
\text { PK 1.5. Meteorological aspects (smoke status, smog, silence and other adverse meteorological } \\
\text { conditions) }\end{array}$ \\
\hline $\begin{array}{c}\text { Group } \\
\text { PK } 2\end{array}$ & $\begin{array}{l}\text { Technical and } \\
\text { technological } \\
\text { indicators }\end{array}$ & $\begin{array}{l}\text { PK 2.1. Transport (cooling water, overhead transmission line, coal / gas / fuel oil, technical gases, slag } \\
\text { and fly ash, accessibility, construction materials, etc.), } \\
\text { PK 2.2. Meteorological and hydrological aspects (safety against flooding, extreme meteorological } \\
\text { phenomena and impact), } \\
\text { PK 2.3. Geology and seismology (seismotectonics and seismic, engineering geology - soil mechanics } \\
\text { and foundation, lithology and geomorphology, neotectonic activity) }\end{array}$ \\
\hline $\begin{array}{c}\text { Group } \\
\text { PK } 3\end{array}$ & $\begin{array}{l}\text { Safety and } \\
\text { security } \\
\text { indicators }\end{array}$ & $\begin{array}{l}\text { PK 3.1. Conditions for delivery of equipment } \\
\text { PK 3.2. Conditions for delivery of raw materials and consumables, } \\
\text { PK 3.3. Environmental risk assessment } \\
\text { PK 3.4. Proximity and danger of impact from other industrial and other risky facilities and facilities }\end{array}$ \\
\hline $\begin{array}{c}\text { Group } \\
\text { PK } 4\end{array}$ & $\begin{array}{l}\text { Economic and } \\
\text { financial } \\
\text { indicators and } \\
\text { energy } \\
\text { efficiency }\end{array}$ & $\begin{array}{l}\text { PK 4.1. Description of cost-benefit analysis units (analysis of investment costs, operating and } \\
\text { maintenance costs, reconstruction, revitalization and modernization costs and costs of removing or } \\
\text { changing the purpose of the facility), } \\
\text { PK 4.2. Analysis of social flows (estimation of investment price distortion, salary, fiscal aspects), } \\
\text { PK 4.3. Analysis of social benefits (effect / output price distortions, social benefits from employment, } \\
\text { external benefits, economic net present value - NPV and cost effectiveness), } \\
\text { PK 4.4. Analysis of additional evaluation criteria, from the aspect of presentation of results from the } \\
\text { point of view of the general objectives of EU standards, increase of GDP, increase of employment, } \\
\text { etc., } \\
\text { PK 4.5. Ability to build cogeneration / hybrid plants as well as other compatible facilities } \\
\text { PK 4.6. Analysis of energy efficiency indicators }\end{array}$ \\
\hline $\begin{array}{c}\text { Group } \\
\text { PK } 5\end{array}$ & $\begin{array}{l}\text { Environmental } \\
\text { aspects and } \\
\text { sustainable } \\
\text { development }\end{array}$ & $\begin{array}{l}\text { PK 5.1. Visual impact and impact on the landscape, } \\
\text { PK 5.2. Biological and ecological sensitivity of the location and its immediate surroundings, } \\
\text { PK 5.3. Environmental protection (nature and cultural heritage, ecological and biological } \\
\text { characteristics, radiological aspects, water quality, soil condition - chemical aggression) }\end{array}$ \\
\hline $\begin{array}{c}\text { Group } \\
\text { PK } 6\end{array}$ & $\begin{array}{l}\text { Specific } \\
\text { indicators for } \\
\text { sustainable } \\
\text { spatial } \\
\text { development }\end{array}$ & $\begin{array}{l}\text { PK 6.1. Preserving the value of space for priority activities of the area, } \\
\text { PK 6.2. The possibility of using more environmentally friendly energy, } \\
\text { PK 6.3. Ability to use new technologies with higher efficiency (cogeneration, tri-generation, combined } \\
\text { steam and gas power generation plants, hybrid systems combined with renewable sources, etc.), } \\
\text { PK 6.4. Holding or reducing the load of already loaded area, } \\
\text { PK 6.5. The primary elimination of conflicts and their alignment with the interests of the protection of } \\
\text { natural heritage, with the need to valorize the landscape (landscapes) and relevant environmental } \\
\text { components, } \\
\text { PK 6.6. Restoration of devastated areas and areas without other activities, } \\
\text { PK 6.7. Employment opportunities and economic development of depopulation areas }\end{array}$ \\
\hline
\end{tabular}

The sustainability of selected energy options requires a detailed and integrated framework for analysis and decision-making, with multiple criteria and multiple decision-making levels, as well as many objective and subjective constraints. Starting from the earlier principle of energy development planning, which meant meeting the requirements of energy consumers with minimal economic costs, it is necessary to additionally include requirements related to the environment and society itself, starting from the earliest stage of design and development of project documentation, where the choice of micro location is important a prerequisite for ensuring sustainable energy development (Bishnoi and Basu, 2005). 
International Journal of Mathematical, Engineering and Management Sciences

Vol. 6, No. 1, 118-165, 2021

https://doi.org/10.33889/IJMEMS.2021.6.1.009

\subsection{Description of the Elimination Criteria for TPP Location Selection}

Taking into account the analyzes carried out and the overview of the activities to date regarding the evaluation process and the selection of macro and micro locations for TPP (given in Table 1 and Table 2), the need to collect a large number of different data and the involvement of a large number of experts from different specialties, as well as the need for transparent public involvement, the decision-making process should be based on exact models of weighting both the good (strengths) and the bad (disadvantages) of each of the potential sites. In doing so, it is very important that the selection of the evaluation criteria depends on the area of interest for choosing the site. This makes it possible to omit certain criteria in the evaluation process in case there are no major differences between the processed sites in the process of its evaluation.

The elimination criterion labeled "EC Group 0 - Compliance with Planning Documentation" includes compliance with spatial planning elements (Sub-criterion EC 0.1), then verifies compliance with energy sector development strategies (Sub-criterion EC 0.2), as well as compliance with economic policy and other short-term plans (energy balance, electricity balance). Sub-criterion EC 0.1 includes the analysis of the consequences of land expropriation and displacement of the population in order to create preconditions for the completion of the macro and micro location of an energy facility or landfill, the spatial consequences of separation of units, as well as the analysis of the impact on the spatial and urban development of the area under consideration. In case of continuation of realization of energy complexes which already have partially realized part of capacities, realization of the following phases represents by function and purpose a logical continuation of energy complex, as foreseen by higher order planning documentation. In this way, the available space was used to build new blocks in previously defined locations. From the point of view of the analysis of the impact on the spatial and urban development of the subject area, those sites are more favorable, which will enable more significant infrastructural development of the wider subject area. Implementation of energy projects will, as a rule, have an impact on stabilization and positive trends, primarily in the labor market and in the construction sector, which will create conditions for higher rates of economic growth. It should be sought that the very purpose of the location and the spatial organization of the planned complex does not necessitate major spatial and urban changes. Micro locations in the immediate vicinity outside a predefined construction zone must not be compromised, which should allow the vitality of the site outside the defined construction zone to remain unchanged and undamaged. Areas not covered by relevant planning, planning and strategic documentation is eliminated. In case the previous studies on the economic viability of the new energy plants show that there is a need and economic and financial suitability for their implementation, a procedure for amending the said documentation is initiated, which leaves the possibility for the considered projects to meet this elimination criterion in the future.

The space required for the accommodation of facilities and facilities of the Main Propulsion Plant (MPP) and ancillary equipment is treated by the EC elimination criteria group 1 . In this case, subcriteria EC 1.1 exists, which considers the main propulsion facility (MPP - boiler, turbine, electric generator), as well as the sub-criterion EC 1.2, which treats auxiliary plants (CWT - chemical water treatment, supply of primary and auxiliary fuels, shipping by-products from the process of exploitation, ecological systems - wastewater, ESF - electrostatic filter, chimney, etc., technical gas system, electrical equipment - switchgear, transformers, etc.). All buildings (buildings) and power plant installations represent a complex technological and architectural complex whose design requires knowledge of technological, economic, environmental, aesthetic and other characteristics. For this reason, the development of the disposition plan requires the active involvement of not only 
International Journal of Mathematical, Engineering and Management Sciences

Vol. 6, No. 1, 118-165, 2021

https://doi.org/10.33889/IJMEMS.2021.6.1.009

experts covering thermal power and electrical engineering, but also of machinists of production orientation, architects, experts in transport infrastructure (roads, railways, etc.), as well as experts in occupational safety, protection health and fire protection etc. In order to place an object in a particular space, it is necessary to define the size of that space on the basis of the known basic dimensions of certain basic equipment and facilities, and their interconnections (in the case of a thermal power unit, that space is defined on the basis of the reference disposition of the thermal power plant facilities). This elimination criterion stems from the technical and safety requirements associated with installation, reliable operation and maintenance during their service life. On the basis of all requirements and conditions for quality layout of the general plan of the power plant, it is necessary to evaluate certain indicators, such as: specific area of the building, $F_{s a}=F / N, \mathrm{~m}^{2} /$ MW, coefficient of utilization of the territory, $k_{t e r}=\left(F_{t o t} / F\right) \cdot 100, \%$, then the coefficient of coverage of the building $k_{c o v}=\left(F_{o c c} / F\right) \cdot 100, \%$, where: $F$ - located in the part of the enclosure TPP $\mathrm{m}^{2} ; N$ - installed TPP power, MW; $F_{t o t}$ - total area occupied by TPP buildings and equipment, $\mathrm{m}^{2} ; F_{\text {occ }}$ - total area occupied by buildings within TPP, $\mathrm{m}^{2}$. The numerical value of the coefficient of construction coverage for modern TPPs and nuclear power plants is 20 to $30 \%$ (part of the area covered by buildings). The dimensions of the required surface for the installation of TPP facilities and facilities should provide the necessary sanitary zone around the power plant (500 to $1000 \mathrm{~m}$ ), depending on the environmental impact of the TPP. The nuclear power plant has a much wider sanitary protection zone (4 to $6 \mathrm{~km}$ ), and it is optimal that there are no larger settlements in the zone with a diameter of 30 to $50 \mathrm{~km}$, as well as other facilities that could additionally adversely affect the environment. On the other hand, given the gradual block realization of TPP facilities, it is often the case that the construction of a new block is already foreseen within the space under consideration.

Conflicts with other spatial content are covered by the EC Group 2 elimination criterion and by seven sub-criteria:

- EC 2.1. Special purpose areas - Military facilities and installations (for coal and gas TPPs, areas planned for military installations and facilities as well as their protection zones are eliminated);

- EC 2.2. Existing and planned population density (aspects of location security: for coal and gas TPPs, areas defined by general urban plans for the growth of larger settlements are eliminated);

- EC 2.3. Tourist and recreational areas (For TPP on coal, areas with more than 10,000 users of space within a radius of $5 \mathrm{~km}$ from the center of the settlement or center of gravity of the settlement group are eliminated);

- EC 2.4. Airport maneuver zones (for coal, gas and gas TPPs, areas of maneuver zones of military, mixed and civilian $\mathrm{A}, \mathrm{B}$ and $\mathrm{C}$ class aerodromes and their protection zones are eliminated);

- EC 2.5. Transport infrastructure (roads and railways);

- EC 2.6. Protection zones from other industrial and commercial buildings (existing industrial complexes and commercial zones);

- EC 2.7. Other (agricultural facilities, water supply systems, etc., for coal-fired TPPs, existing large landscaped (reclaimed) agricultural areas on soils that are highly suitable for agricultural development are eliminated).

The elimination criterion "Group EC 3 - Technical and technological aspects of the location" include the analysis of the fulfillment of the elimination conditions related to the quantity and transport of cooling water required (sub-criterion EC 3.1), flooding danger (sub-criterion EC 3.2), electricity aspects of connection to the transmission network (sub-criterion EK 3.3), settlements gas network (sub-criterion EC 3.4), settlements - heating grid (sub-criterion EC 3.5), settlements - 
International Journal of Mathematical, Engineering and Management Sciences

Vol. 6, No. 1, 118-165, 2021

https://doi.org/10.33889/IJMEMS.2021.6.1.009

water supply network (sub-criterion EC 3.6) and exploitation of ores and minerals (sub-criterion EC 3.7). For coal-fired TPPs and gas-fired TPPs, areas with watercourses with a minimum flow rate, less the total planned consumption of other users and a biological minimum amount of less than $1 \mathrm{~m} 3 / \mathrm{s}$, are eliminated. Coal and gas TPPs eliminate areas more than $10 \mathrm{~km}$ from the watercourse, or $5 \mathrm{~km}$ from the coastline, as well as areas with a height difference greater than 40 $\mathrm{m}$ from the assumed water intake location. For coal-fired TPPs, existing and planned areas foreseen in the flood protection system for high-water retardation are eliminated. From the aspect of fulfillment of EC 3.3, islands more than $2 \mathrm{~km}$ from the mainland are eliminated for coal and gas TPPs, and from the aspect of EC 3.4 for gas TPPs are eliminated areas more than $100 \mathrm{~km}$ away from the routes of planned main and transit gas pipelines with larger capacities in the wider regional area. For coal-fired TPPs, spaces that are more than $10 \mathrm{~km}$ away from the main network of the heat grid are eliminated for steam or more than $20 \mathrm{~km}$ for hot water pipelines, with application only for thermal power plants - heat plants (sub-criteria EC 3.5 and 3.6).

The elimination criteria related to "EC Group 4 - Economic and financial aspects of construction and / or work" are considered through the following sub-criteria:

- EC 4.1. Investment specific construction costs (for coal-fired TPPs with installed power above 50 MWe on coal do not have to exceed $\$ 1500 / \mathrm{kWe}$, with a construction period of four to five years and a preparatory period for the implementation of the maximum of two years, for gasspecific power plants construction need not exceed the $\$ 800$ / kWe limit);

- EC 4.2. Costs of exploitation (operation) and maintenance (at a discount rate of 5\%, the leveled costs of generating electricity for most coal-fired power plants do not exceed $\$ 50$ / MWh, while at a discount rate of $10 \%$, the leveled costs of generating electricity for most coal-fired power plants have a limit of $\$ 60 / \mathrm{MWh}$ );

- EC 4.3. Fuel costs (for TPP on coal they do not need to exceed 35\%, for TPP on gas the cost of fuel remains the main participant and can reach up to $75 \%$ maximum);

- EC 4.4. Expenditure related to the impact of greenhouse gas emission limitation (emissions from installations covered by the EU ETS in 2017 increased slightly compared to 2016 - by $0.18 \%$. This, however, halted the downward trend since the beginning the third trading period under the system (2013-2020), this increase can be explained by a real GDP growth of $2.4 \%$, which is higher than in any year since the beginning of the trading period emissions from the energy sector have fallen slightly for the fourth consecutive year);

- EC 4.5. Economic life of power plants (describes the time period in which investment in power plants should return, with technical life usually longer than that - the technical life of a nuclear power plant is 60 years and the budget uses an economic life of 40 years, requiring annual investment maintenance to achieve this is included in the cost of operation and maintenance, the other power plants use an economic life of 25 years, and their operating and maintenance costs do not include any specific annual maintenance investment);

- EC 4.6. Economic profitability of investing in power plants (depends on the competitiveness of production costs and the market price of electricity. Emissions restrictions and emission prices have a clear impact on the future development of electricity prices in the market, which is clearly on the rise. The 2013 futures price is $53 € / \mathrm{MWh}$, and the price can be in the order of 60 to 70 $€ / \mathrm{MWh}$ around 2020. The return on investment and other indicators of profitability of the investment in nuclear energy are calculated using market prices from 40 to $70 € / \mathrm{MWh}$ );

- EC 4.7. The ratio of returned and invested energy (in physical, energy-economic and environmental-energy terms, energy returned on energy invested (EROEI) or energy returned on investment (EROI), is the ratio of the amount of utility energy obtained from a particular 
International Journal of Mathematical, Engineering and Management Sciences

Vol. 6, No. 1, 118-165, 2021

https://doi.org/10.33889/IJMEMS.2021.6.1.009

energy source by the amount of energy consumed to produce that energy source, and according to the concept of Energy return on investment (EROI) by Professor Charles Hall, SUNY College of Environmental Science and Forestry, EROI value for coal is 80, for natural gas 2005 and nuclear fuel with diffusion enrichment is 10 and 50 for nuclear year with centrifugal enrichment, with fast or thorium reactor), oil and gas 1970 has an EROI of 50, while oil and gas 2005 has an EROI of 14.5).

Security aspects and risk are covered by Group EC 5 and consider the following sub-criteria:

- EC 5.1. Seism-tectonics (for coal-fired TPPs and gas-fired TPPs, areas with the maximum possible intensities of the IX to X earthquake and higher MCS scale are eliminated);

- EC 5.2. Neo-tectonics (For TPPs on coal and gas TPP spaces in the zones of nominated active faults are eliminated);

- EC 5.3. Hydrogeology (drinking water sources: areas for protection of drinking water sources are eliminated for coal-fired TPPs and for gas-fired TPPs according to the Rulebook on protective measures and conditions for determining zones of sanitary protection of drinking water sources; waste should not be in areas with significant aquifers of any type);

- EC 5.5. Litho-logic and geomorphologic characteristics (for landfill eliminated are areas with increased erosion caused by litho-logical composition or dynamic relief; built from rocks unstable in natural conditions and during construction activities. Eliminated are landslides and lands prone to collapse if threatened by external objects of the landfill; Because of their peculiarities, and the relief, with their dynamics, significantly affect the stability and bearing capacity of the terrain (these are the features of particular importance in the construction of structures whose integrity is a prerequisite for environmental safety), all of them are rejected from the further process of choosing a landfill location areas where more pronounced slope processes have been identified: landslide, collapse, rash, rinse, as well as the occurrence of torrents or poor bearing capacity of the terrain);

- EC 5.6. Topography (TPP objects, because of the size of the plateaus they occupy and the necessary conditions for foundation or foundation, it is not advisable to locate in areas with a slope of more than 5\%, on riverbeds of drained rivers, notches, passes, plateaus at higher altitudes in relation to the environment and similarly, all of these areas are excluded from consideration for the placement of a thermal power facility, with higher slope areas not providing other technical, technological and safety requirements);

- EC 5.7. Settlements - density and safety aspects of the site (density: eliminates areas for TPPs with a cumulative population density of $20 \mathrm{~km}$ greater than 200 inhabitants per $1 \mathrm{~km} 2$, while landfills eliminate areas with a cumulative population density of $20 \mathrm{~km}$ greater than 80 inhabitants per $\mathrm{km} 2$, safety aspects of the location: for coal and gas TPPs, areas defined by the general urban plans for the growth of larger settlements are eliminated).

Environmental aspects and environmental protection in life-cycle periods (construction, operation, revitalization, reconstruction and modernization and removal of facilities), EC Group 6 includes a fulfillment analysis:

- EC 6.1. Protection of natural heritage (for coal and gas TPPs, areas of national parks, nominated nature parks and other significant nature reserves are eliminated);

- EC 6.2. Protection of cultural heritage (for TPP on coal and gas TPP, areas of cultural property, listed in the list of world cultural and natural heritage, large and larger spatial units, spaces of cultural assets that are of utmost importance and great importance for the social community are eliminated, except within already planned industrial zones outside the settlement); 
International Journal of Mathematical, Engineering and Management Sciences

Vol. 6, No. 1, 118-165, 2021

https://doi.org/10.33889/IJMEMS.2021.6.1.009

- EC 6.3. Protection of biological and ecological values (for coal-fired TPPs, areas of high biological potential that are under special protection regimes are eliminated);

- EC 6.4. Social aspects - right and impartial distribution of energy sources, energy systems make accessibility and availability of energy systems and acceptability of energy prices (energy indicators: fairness-accessibility, accessibility and diversity, health-safety, with elimination of technologies with more accidents and injuries per energy produced in the energy production chain);

- EC 6.5. Sociological values of threatening nature (sociological consequences of some form of threatening nature as a public good - eliminated are areas with extreme sensitivity to the occurrence of an accident, development of an adverse scenario, events, adverse intervention, introduction of some risk element, etc.).

\subsection{Description of Comparison Criteria for TPP Location Selection}

The basic criteria and conditions that will be applied in the process of comparison and selection of TPP micro-locations within the selected macro-location are defined in Table 2.

The first set of comparison criteria is related to spatial-planning conditions (Group PK 0) and includes the following sub-criteria for evaluation: the potential for conflict in the space with other users of the space, then the relations of the location to the protected parts of the location and in its vicinity, as well as the purpose and use of space (demography and settlement, agriculture and forestry, industry and mining, education and education).

The potential for conflict in space with other users of space (PK 0.1) is an extremely important criterion, created as a result of occupying the relatively large space required for TPP, as well as the need for additional protection zones. Conflict with other users of the space is possible, whereby valuations are better for those micro-locations whose value and utilization is less for other real users or potential users of the space in the future, and if the number of those users is smaller. Most often, the value function is formed by the equation:

$P K_{0.1}=10-K_{0.1}$,

where, $K_{0.1}$ is obtained as the sum of negative points: one negative point if the micro location area is defined as: agricultural land of the first category, water protection area (II and III zones), area of sports and recreational use, farm of fish or other river or marine organisms, two negative points for each following area at a micro location distance for a coal-fired TPP of up to $10 \mathrm{~km}$, or for a gasfired TPP of up to $5 \mathrm{~km}$, defined as: a hospitality-tourism area, a residential-tourist area.

The relation of the location to the protected parts of the area in and near the location (PK 0.2) not covered by the elimination criterion EC 6 (protected areas: strict or special reserve, national park, nature monument, park architecture of interstate and state values) is given as function of value, formed by the equation:

$P K_{0.2}=10-K_{0.2}$

where, $K_{0.2}$ represents the sum of negative points: two negative points in case the micro location area overlaps with the area of a special reserve or landscape of local importance or is categorized as an area of protected or special purpose forests, one negative point for the recorded area as cultural 
International Journal of Mathematical, Engineering and Management Sciences

Vol. 6, No. 1, 118-165, 2021

https://doi.org/10.33889/IJMEMS.2021.6.1.009

and historical heritage, one negative point in case the area of a special reserve or landscape of local importance or a categorized area of protected or special purpose forests is located within a radius of $1.5 \mathrm{~km}$ from the center of the potential micro-location for TPP.

A sub-criterion covering the use and use of space in terms of demographics and population, the presence of extensive occupation in agriculture and forestry, industry and mining, school system and education (PK 0.3) should cover all risks of people with permanent or temporary residence in close proximity selected micro locations, where for each planned micro location in addition to already constructed capacities are considered. The value function is formed by the equation:

$P K_{0.3}=10-K_{0.3}$,

where, $K_{0.3}$ represents the sum of negative points: one negative point for TPP locations with a diameter of 10 to $30 \mathrm{~km}$ for each settlement with more than 10,000 inhabitants, with more pronounced central and working functions, one negative point for TPP locations with a diameter of 10 and $5 \mathrm{~km}$ respectively for landfill for each small share of areas suitable for agricultural development, as well as a smaller share of high value forest areas, taking into account the ecological role and stability of the forest as well as by-products such as edible mushrooms and medicinal plants, one a negative point for coal-fired TPP sites with a radius of up to 10 and $5 \mathrm{~km}$, respectively, an industrial center, a represented mineral exploitation field, or a sensitive food and pharmaceutical industry, one positive mark for coal-fired TPP sites with a diameter of up to 10 to $30 \mathrm{~km}$ the number of industrial and labor centers of greater importance, and where there is greater representation in those centers activities with significant electricity consumption, that is, for landfill locations with connection to infrastructure installations (water supply, electricity grid), one negative point for TPP locations with a share of main and regional infrastructure (transport, oil pipelines up to $10 \mathrm{~km}$ ) and pipelines, product pipelines and water pipelines), one negative point for coal-fired TPP sites within $30 \mathrm{~km}$ of which existing or planned tourist capacity is recorded, and if these capacities have shorter usage times during the year, one negative point for TPP on coal locations, TPP on gas and landfill that have limitations or other special requirements from the point of view of defense.

The PK1 criteria group, through five sub criteria, treats the most important geologic-seismological indicators of potential micro locations. Coal and landfill TPP and gas TPP are more favorable locations in areas with lower maximum expected earthquake intensity and in non-tectonically less active zones, as well as locations composed of only one type of rock and locations where no liquidation is expected. The more unfavorable the natural conditions at the location (the higher the slope of the terrain, the surface layer of soil of poorer geomechanical characteristics with less allowable load), the worse the location.

The first sub-criterion PK 1.1 includes the analysis of seismological and seismotectonic indicators. Seismology is a science that deals with the study of earthquakes and all its consequences. As a relatively young scientific field of geophysics, seismology studies the processes that cause earthquakes, the movement of seismic waves so created through the Earth's crust and its deeper interior, and the destructive effects of seismic waves on objects and soil. The occurrence of earthquakes that are relevant to the created environment is related to the splitting of rock mass in the earth's crust, or to seismogenic faults, so when planning the construction of energy facilities, care should be taken that they are not located near these living faults. The starting point for defining an earthquake is a seismological map. It gives a seismic hazard for a given space and for some time 
interval with probability of occurrence, as well as hazards on the selected ground. General seismic hazard has a number of partial elements (e.g. tectonic, geological, engineering-geological hydrogeological, geomechanical, etc.) and their synthesis defines the general seismic hazard and expresses it in the engineering parameters of seismicity. Seismic risk itself defines the level of damage that an earthquake does to the created environment. Earthquakes are rare and therefore determine the level of protection that a society can accept according to its economic potential and this is defined by acceptable seismic risk. In the former Yugoslavia (1945 to 1991), since 1990, a seismological map drawn up by the Seismology Association of the SFRY was officially used, which had six oleats related to earthquake feedback periods of 50 (Figure 3), 100, 200, 500, 1000 and 10000 years, with the probability of intensity occurrence being $63 \%$ on the average soil covered by isolation of the same intensity. For the purposes of the earthquake calculation, oleate with a return period of 500 years was used for objects of the second and third categories. Thus, at that time, the requirement of valid Euro code 8 EN 1998-1: 2004 for the "object not to collapse" was used to define the seismic hazard, using the same earthquake return period.

There are two basic approaches to building security approaches - a deterministic and probabilistic understanding of security. A deterministic understanding of safety was used in the first calculation methods (the allowable voltage method). It assumes a secure construction, when the stresses from the external load are less than the prescribed allowable stresses. The permissible stresses are related to the safety factor with certain limit values (e.g. yield stress, strength). The probabilistic understanding of safety is based on the assumption that there is no completely secure construction. Each structure or structural element has some probability of bearing failure. For the calculation, all variables need to be statistically processed and used in the form of functions of a certain probability distribution (most often proving safety at 4 levels).

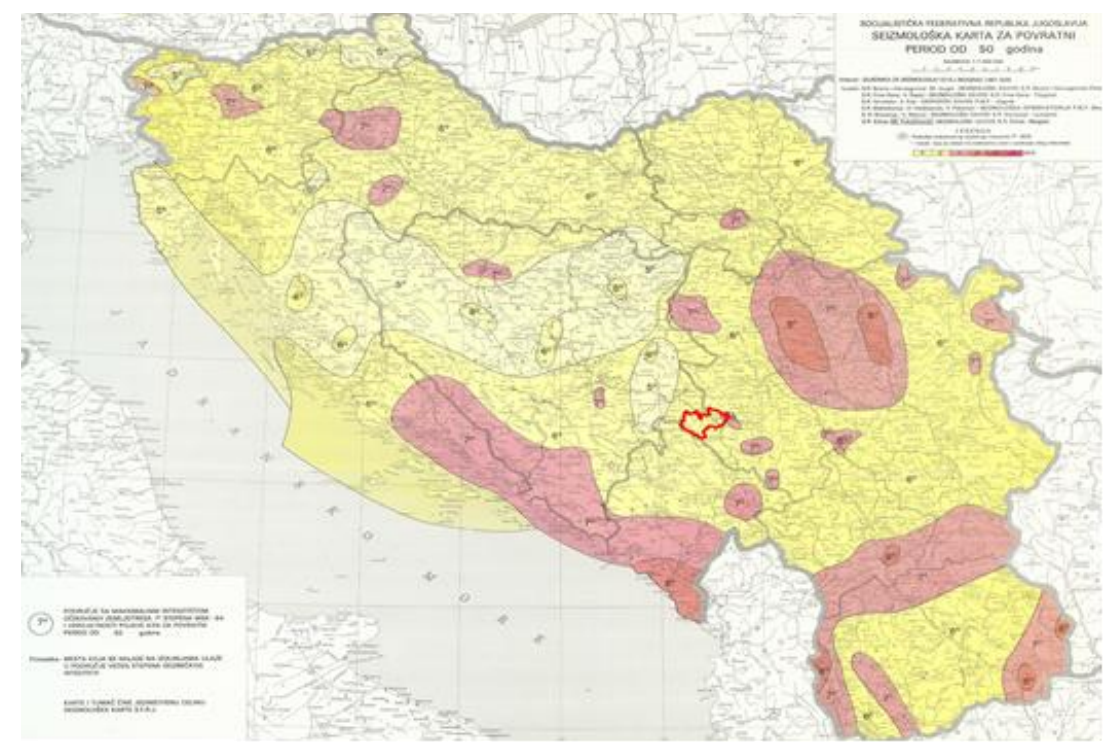

Figure 3. Seismic map of ex SFRY for a return period of 50 years, Seismology Community of SFRY, (Milovanović et al., 2011c). 
International Journal of Mathematical, Engineering and Management Sciences

Vol. 6, No. 1, 118-165, 2021

https://doi.org/10.33889/IJMEMS.2021.6.1.009

The rating of this sub-criterion is equal to the function

$P K_{1.1}=\left(P K_{1.1 .1}+2 \cdot P K_{1.1 .2}+2 \cdot P K_{1.1 .3}+P K_{1.1 .4}\right) / 6$,

where, $P K_{1.1 .1}$ to $P K_{1.1 .4}$ defined sub-parameters of sub-criterion PK 1.1 are defined as follows:

- Sub-parameter $P K_{1.1 .1}$ describes seismotectonic relationships in the wider area of the location and has a value of 1 to 6 ( 1 - within the reverse structure, less than $0.5 \mathrm{~km}$ away from the fault zone or its branches, within the boundary reverse structure fault zone; 2- within the reverse structure, less than $1.0 \mathrm{~km}$ away from the fault zone or its branches, located within the border zone of the border structure; 3- inside the reverse structure, away from the zone of the fault or its branches more than $1.0 \mathrm{~km}$, outside the border zone of the border; 4- within the reverse structure in the zone of accompanying faults, less than $1.0 \mathrm{~km}$ from that zone; 5 - within the reverse structure in the zone of supporting faults, away from that zone and its main branch more than $1.0 \mathrm{~km}$ and 6 - relatively small rock fragmentation within the reverse structure, away from the nearest fault boundary to the local structure, outside the contact areas of the regional structural units);

- the sub-parameter $P K_{1.1 .2}$ describes the acceleration on the base rock obtained by the probabilistic method, where the value function is defined as $P K_{1.1 .2}=2^{10 \cdot(0,5-a)}$, where $a$ the given horizontal acceleration (acceleration) is expressed in $g$, with the score for $a \geq 0,50 \cdot g$ being equal to 10 and for $a \geq 0,50 \cdot g$ equal to 1 ;

- sub-parameter $P K_{1.1 .3}$ describes the acceleration on the base rock obtained by the deterministic method, it is defined similarly to the previous subparameter;

- sub-parameter $P K_{1.1 .4}$ describes the effect of soil (such as topographic features, shaking resonance, etc.) on the location on the magnitude of the earthquake force (soil characteristics can increase the tremor during an earthquake - soft and weakly connected soil can shake more strongly than rocky ground, although they are equally distant from the rock. earthquake epicenter, which can significantly increase earthquake damage), and is expressed via the HVSR index - Horizontal to Vertical Spectral Ratio index: $P K_{1.1 .4}=10$ if it is a pure base rock on the surface, $P K_{1.1 .4}=9$ if HVSR is 1,2 and 1,4 , then $P K_{1.1 .4}=8$ if the HVSR is 1.4 and 1.6 and $P K_{1.1 .4}=7$ if the HVSR is greater than 1.4.

Local geological indicators represent the second sub-criterion designated PK 1.2, and include those parameters that may affect the foundation of individual facilities and plants at the TPP or landfill, as well as their static and dynamic stability. It covers the parameter of geotechnical and engineering-geological qualification, such as soil composition, karst phenomena, lithological profile, soil settling potential, slip potential, liquefaction, etc. Liquidfaction is a phenomenon that occurs in the light, water-saturated sands of a narrow or uniform granulometric composition, at the moment of a cyclic change in the stress state caused by an earthquake. A cyclic change in the stress state causes the soil to shake, which loses its shear strength and acts as a viscous fluid. Two conditions must be fulfilled at the same time for the liquidation: the soil must be light, saturated with water, sandy and at a depth of 0 to 10 meters below the soil surface and an earthquake must be strong enough to cause the soil prone to liquidation to start. From the above, it is obvious that it is possible to identify areas that are prone to liquidation, globally, as well as the possibility of the same occurrence locally. For this purpose, it is necessary to determine the degree of liquefaction potential, through determining the degree of seismicity of the area, as well as soil properties. As 
determining the degree of seismicity falls within the geophysical profession, determining soil properties is a purely geotechnical task. On the basis of preliminary maps of the degree of likelihood of occurrence of country-specific liquidation, it is preliminary determined the likelihood of the occurrence of liquidation associated with the determination of earthquake zones with a return period of 100 years. A high "liquefaction potential" implies a probability of greater than $50 \%$ and a very small less than 5\%. The proper soil condition at the location is usually determined only after detailed engineering-geological surveys have been carried out, while at the level of study documentation related to the feasibility analysis of the project realization, the process of comparison and evaluation is based on field review, analysis and reinterpretation of previous works and expert evaluation. It is determined by function

$P K_{1.2}=\left(P K_{1.2 .1}+P K_{1.2 .2}\right) / 2$,

where with $P K_{1.2 .1}$ and $P K_{1.2 .2}$ are defined under the parameters of sub-criteria PK 1.2 as follows:

- sub-parameter $P K_{1.2 .1}$ describes the hydrogeological conditions at the location (stability of the terrain during construction of the construction pit, as well as the interaction of the planned intervention with the groundwater during construction and during operation) in the form of grades 1 to 10 (1- location in a high zone of sanitary protection of drinking water sources with possible direct by affecting the sanitary condition of the well, groundwater directly threatens the stability of the object, 2- the location is wholly or partially located in high zones of protection of the drinking water well with a possible direct impact on the sanitary condition of the wells, I and II zones, 3- the location with the zones sanitary protection of drinking water sources with possible impact on the source, III and IV zones, 4- location with locations outside the sanitary protection of drinking water sources, but with deep interference a disturbance that threatens the source itself is possible, stronger influence of groundwater on the construction of the facility, 5location with locations outside the sanitary protection zone of drinking water sources, but in the wider location there are stronger coastal springs, possible influence in high waters on the foundation of the building, 6 locations with locations outside the sanitary protection zone of drinking water sources, but in the wider location there are smaller coastal sources, possible minor impact in rainy periods on the foundation of the building, 7 - location outside the sanitary protection area of drinking water sources, but possible impact of the sea or lake and deep into the land due to pronounced crevices, and sediments, 9 - location outside the sanitary protection zone of drinking water sources, but possible impact on water in karst underground in the coastal area, 10 - watertight solid rocks without groundwater and without the possibility of infusion of water into the underground - granite);

- sub-parameter $P K_{1.2 .2}$ describes the engineering-geological (geotechnical) conditions at the location, such as relief, lithological composition, structural, some hydrogeological and physicalmechanical properties and modern geodynamic processes, in the form of grades 1 to 10 (1- solid carbonate rock completely fractured and transformed into a tectonic breccia with clay, 2 -solid carbonate rock with numerous wide fault zones and cavern appearance, alteration of lithologically different types of rocks in location, 3-solid carbonate rock broken into blocks with numerous strong faults, fault zones up to $10 \mathrm{~ms}$ wide breccia and clay, 4- very fractured solid carbonate rocks with slopes unfavorable to the slope, strong faults occur, 5- solid carbonate rocks broken into blocks with a strongly cracked system with clay fill, strong faults, 6- solid carbonate rocks with pronounced crack system with clay fill, faults, 7- thick layers limestones with pronounced fissure systems, proximity to transgressive discordant contact, 8 - layered to 
International Journal of Mathematical, Engineering and Management Sciences

Vol. 6, No. 1, 118-165, 2021

https://doi.org/10.33889/IJMEMS.2021.6.1.009

flat limestones with poorly fissured systems, 9- layered to flat limestones compact, 10-solid completely undamaged carbonate and eruptive rocks without pronounced fissure systems.

When studying terrain relief, it is necessary to collect data on the shape and range of terrain (flat, hilly, hilly and mountainous terrains), the presence of the sea, lakes and river beds and the problems that arise regarding the management of larger river flows, shallow groundwater levels, possible occurrences ponds and wetlands (insufficient load-bearing capacity), as well as the absence of geological building materials for embankment construction. When studying the lithological composition, the data on the lithological type of rock mass, spatial position, mode of occurrence, thickness of the surface decay, the existence of layers and lenses of clay and sludge, thickness and type of river application should be collected. The structural spatial properties of the terrain should be studied in relation to the spatial positions of the lithologic members, the well-being, the outgrowth, the crack and the spatial position of the faults and cracks. The rock masses were the least damaged and cracked. Particular attention should be paid to determining the existence of faults along the river flow, since usually the river flow is predisposed to faults and if these faults are active. Knowledge of the physical-mechanical properties of rock masses is necessary for the execution of works (foundation of columns, access to an object by filling or cutting). For loosely bound and unbound rock masses the granulometric composition, volume weight, porosity, water content in the natural state, boundaries of plasticity, cohesion, internal friction angle, compressibility modulus, etc. are required on the ground crack, the existence of caverns, decay, etc. From hydrogeological properties it is necessary to determine whether rock masses are with the function of hydrocollectors or waterproofers. In addition, it is necessary to establish the chemical composition of groundwater and water in the river in order to determine the aggressiveness of water to concrete and other building materials. From modern geodynamic processes it is necessary to study fluvial erosion (whether erosion deepens the bed or sub-basins, existence of deep erosion grooves - giant pots, filled with modern river bed), slippage most often occurs in the slopes of those parts of the river stream where curvature of axes occurs, due to the impact of the river nut and the subsoil of the coast, landslides most often occur in steep gorges and canyon valleys from higher parts of the slope, which can lead to damage to the structure; Detection of fossilized dredges can lead to its activation and landslide formation, underground karst forms, i.e., cavities can break below the foundation pillar either during construction or during exploitation, the seismicity of the terrain significantly influences the construction, therefore it is necessary to know the degree of seismicity. Due to the load on the object and the work carried out by the load-bearing columns to the substrate, the substrate settles. Deposits in sandy-sandy substrates are carried out during construction, while settlements in marl-clay sediments can last for many, many years. The largest settlements of bridge piers are if they are on muddy ground. Which way to support load-bearing columns depends on the engineering-geological properties of the rocks in the substrate, so if the substrate consists of rocky and semi-rocky rocks, then a shallow foundation is usually performed, while for the substrate made of silt, peat, loose sand and similar rocks of low bearing capacity and large compressibility deep foundation is applied with piles, diaphragms, wells and sometimes caissons.

Sub-criterion PK 1.3 includes the analysis of hydrogeological indicators (groundwater and sources). Gas TPPs are more favorable locations where there are no significant groundwater supplies that are or will be used for water supply. More favorable are those locations where groundwater is protected from the possible penetration of pollution from the surface and where infiltration and flow conditions provide a high degree of sorption and low migration of radionuclides (unstable nuclei of chemical elements that are transformed to a stable nucleus by 
International Journal of Mathematical, Engineering and Management Sciences

Vol. 6, No. 1, 118-165, 2021

https://doi.org/10.33889/IJMEMS.2021.6.1.009

emission of ionizing radiation). The term sorption means two processes - adsorption and absorption. Adsorption in the broadest sense means a change in the concentration of a component of a liquid or gaseous phase at the boundary surface of the phases of a heterogeneous system (solid / gas, solid / liquid, liquid / gas, liquid / liquid), while absorption is a process of even distribution of the total amount of a component of liquid or gaseous phases into solid or liquid phases, which play the role of solvent. From a hydrogeological point of view, the most important indicators are the porosity and water permeability of rock masses. Generally speaking, gravel and sandy rocks are the most favorable environment for groundwater accumulation. Clays, magmatic and metamorphic rocks are in principle unfavorable environments unless there are fissures or tectonic bends. Specific criteria apply to carbonates. The most important for the urbanization of an area of hydrogeological features are: water permeability, the level issued and its oscillation, water flow and the possibility of water supply. The value function is given in the form of grades 1 to 4 (1- optimally favorable terrain if the water permeability is greater than $0.25 \mathrm{~cm} / \min$ and depth issued is greater than $12 \mathrm{~m}$; 2favorable terrain if the water permeability is $0.05-0.25 \mathrm{~cm} / \mathrm{min}$, and depth issued $3-12 \mathrm{~m}, 3$ conditionally favorable terrain, if the water permeability is $0.025-0.05 \mathrm{~cm} / \mathrm{min}$, and depth issued 1-3 $\mathrm{m}$ and 4- unfavorable terrain with a water permeability less than $0.025 \mathrm{~cm} / \mathrm{min}$, while the issue depth is less than $1 \mathrm{~m}$ ). Regardless of the depth, all terrains are favorable, where the maximum level is issued at a depth of more than $2 \mathrm{~m}$ below the lowest foundation angle. Otherwise, an indicator of aggression issued (aggression against concrete, iron and stone - the basic materials of the foundation) appears. Clearance depends on the slope of the terrain, where on terrain I and II the conditions of convenience are light and influenced by gravity, and on terrains III and IV it is large and requires additional limitation of drainage due to denudation and erosion).

Hydrological indicators include all that can be measured and expressed in hydrology, such as water levels, flows, water depths, turbidity, sediment transport, etc. - dispersion of waste heat, dispersion in water, distance of surface flows from landfills, etc., and are covered by PK 1.4 sub-criterion. For TPP locations, hydrological criteria define the vulnerability of the TPP location to surface and groundwater, as well as the needs for the supply of TPP with water, and thus have safety, technological and economic significance in this manner. On the basis of time series of hydrological data, analyzes or calculations of the likelihood of occurrence of the following hydrological quantities are most often performed: maximum and minimum water levels, mean annual flows, mean annual leakage volumes, maximum and minimum flows, maximum volumes of large water waves, mean annual river sediment transport. annual volumes of river sediment transport, maximum, minimum and medium groundwater levels, etc. In the ranking of TPP micro-locations and landfills, the following parameters are included: floods (criterion of maximal half-wave with a return period of 10,000 years), water supply, groundwater and possibility dispersions of liquid radioactive effluents. Water, along with energy fuel, is the most important raw material in the process of energy transformation in thermal power plants (TPP), thermal power heating plants (TPHP), heating power plants (HPP) and industrial power plants (IPP). Modern power plants of the power plants need large quantities of water $\left(60\right.$ to $70 \mathrm{~m}^{3} / \mathrm{s}$ per 1,000 MW of installed cooling capacity). Thus, the water consumption of the condensing power plant through the cooling system of $1 \mathrm{MW}$ of installed capacity is approximately $200 \mathrm{~m}^{3} / \mathrm{MWh}$, or about $55 \mathrm{l} / \mathrm{sMW}$ (for a typical $300 \mathrm{MW}$ power plant, it is about $60,000 \mathrm{~m}^{3} / \mathrm{h}$, or about $16,700 \mathrm{l} / \mathrm{s}$ ). In a cooling tower with a cooling tower, the consumption of additional water to supplement the cooling system per $1 \mathrm{MW}$ of installed power is approximately $5 \mathrm{~m}^{3} / \mathrm{MWh}$, or $1.38 \mathrm{l} / \mathrm{sMW}$ (for a power plant of $300 \mathrm{MW}$ is about $1,500 \mathrm{~m}^{3} / \mathrm{h}$, or about $420 \mathrm{l} / \mathrm{s}$ ). Available quantities of water are one of the most important factors in choosing a location for the construction of TPPs, taking into account additional reserves, as well as minimum quantities in adverse climatic (dry) periods, as well as conditions in which the 
International Journal of Mathematical, Engineering and Management Sciences

Vol. 6, No. 1, 118-165, 2021

https://doi.org/10.33889/IJMEMS.2021.6.1.009

return of water to nature will not cause significant environmental impact (provide biological minimum flow). Non-treated water for safety purposes includes cooling water for condensers and other components at the power plant, process, consumption, sanitation, fire and other water. Required amount of water consumed for steam condensation in turbine condensers $(93 \div 96 \%)$, for hydrogen cooling in generators and air cooling $(2.4 \div 3.7 \%)$, for cooling oil of turbogenerators and steam-turbine power pumps $(1.1 \div 2.3 \%)$, for cooling bearings of auxiliary propulsion machines $(0.3 \div 0.7 \%)$, then for the hydraulic transportation of slag and ash $(0.1 \div 0.4 \%)$, as well as for settling losses of steam and condensate in the working process of the thermal power plant $(0.4 \div 0.9 \%)$. Thus, the main consumers of water in thermal power plants are condensers, while for other consumers up to $7 \%$ of cooling water flow through condensers is consumed. At the beginning of the design of the power plant, it is necessary to draw up a water balance, with two categories of water - water essential for the safety and security of TPP operation, as well as water that is not important from the aspect of safety in the operation of the power plant, but whose lack compromises its economy, as one of the basic elements on the basis of which the choice is made for the choice of macro location and finally the most optimal micro location of objects. The sources of water supply for a thermal power plant may be rivers, lakes and seawater (in the case of its construction on the coast). The most commonly used water sources are rivers, with different cooling systems depending on the available mean water flow and its change during the year (flow duration curve). Water supply systems can be designed as flow (open), return (closed), mixed and combined. Groundwater is a negative feature from the standpoint of foundation in normal and emergency modes. The requirement to ensure minimum security of this requirement is that the groundwater level does not exceed 1 to $1.5 \mathrm{~m}$ below the foundation or at least below the floor of the room where radioactive materials are handled. Also, the choice of location should in case of accidental discharge of a larger amount of radionuclides provide their required dilution, which in the case of using water as a recipient requires better dispersion characteristics, higher quantity and better water quality, as well as greater distance from the user. Coal TPPs are more favorable locations for which the assumed dispersion of waste heat is higher, as well as locations for which, either upstream or downstream, there are no (or at a greater distance) existing or planned thermal power facilities that heat the watercourse. Limiting average values of hydrological parameters of the location that were common in the territory of ex-Yugoslavia were: maximum flood wave with a return period of 10,000 years, minimum water flow of watercourse about $10 \mathrm{~m}^{3} / \mathrm{s}$, minimum water flow of watercourse for flow cooling or minimum volume of reservoir or surface reservoirs $Q_{\text {flow }}=(3 \div$ 4). $Q_{\text {wat.cool }}$ of about $12 \mathrm{~km}^{2}$, elevation of the terrain of the power plant above the mean water surface of the water source from about 20 to $30 \mathrm{~m}$, distance of the power plant from the source of the cooling water or length of the pipeline not exceeding $10 \mathrm{~km}$, maximum increase of the water temperature after complete mixing with the cooling water ${ }^{\circ} \mathrm{C}$, maximum water temperature after complete mixing at $28{ }^{\circ} \mathrm{C}$, minimum groundwater level relative to foundation level 1 to $1.5 \mathrm{~m}$, as well as water dispersion characteristics. The value function is given in the form

$P K_{1.4}=10-K_{1.4}$,

where, $K_{1.4}$ is the sum of the negative points obtained as follows: no negative points for the case of a flow or open cooling system, maximum increase in temperature after mixing in summer up to 1 ${ }^{\circ} \mathrm{C}$ and winter 2 to $3{ }^{\circ} \mathrm{C}$, minimum groundwater level relative to the level of foundations 1 to $1.5 \mathrm{~m}$ good water dispersion characteristics, one negative point for the return or closed cooling system, maximum rise in temperature after mixing in summer 1 to $2{ }^{\circ} \mathrm{C}$ and winter 3 to $4{ }^{\circ} \mathrm{C}$, minimum groundwater level in relation to foundation level up to 1 to $1.5 \mathrm{~m}$ good water dispersion 
International Journal of Mathematical, Engineering and Management Sciences

Vol. 6, No. 1, 118-165, 2021

https://doi.org/10.33889/IJMEMS.2021.6.1.009

characteristics, two negative points for mixed cooling system, maximum increase in temperature after mixing in summer 1 to $2{ }^{\circ} \mathrm{C}$ and winter 3 to $4{ }^{\circ} \mathrm{C}$, minimum groundwater level relative to foundation level 1 to $1.5 \mathrm{~m}$ and good water dispersion characteristics, and three negative points for the combined cooling system, maximum temperature increase after stirring in summer up to $3{ }^{\circ} \mathrm{C}$ and in winter up to $4{ }^{\circ} \mathrm{C}$, minimum groundwater level in the ratio $\mathrm{u}$ to a foundation level of 1 to 1.5 $\mathrm{m}$ and good water dispersion characteristics.

From the perspective of sub-criterion PK 1.5, which covers meteorological aspects (smoke status, smog, silence and other adverse meteorological conditions). Coal TPPs are more favorable locations where the impact on air pollution due to meteorological phenomena in the narrow area is less (less frequent and the creation of smoke, silence and other adverse meteorological conditions). Coal TPPs are more favorable locations where, due to the favorable meteorological and orographic characteristics, the impact on particularly sensitive users of the space is less than $30 \mathrm{~km}$ away from the potential location. The value function is given in the form

$P K_{1.5}=10-K_{1.5}$,

where, $K_{1.5}$ represents the sum of negative points obtained as follows: one negative point in case one of the observed parameters (lower frequency and creation of smoke, smog, silence and other adverse meteorological conditions) is above the permitted values; two negative points in case two of the observed parameters (lower frequency and generation of smoke, smog, silence and other adverse meteorological conditions) are above the permitted values; three negative points in case three of the observed parameters (lower frequency and creation of smoke, smog, silence and other adverse meteorological conditions) are above the permitted values; four negative points in case all four of the observed parameters (lower frequency and generation of smoke, smog, silence and other adverse meteorological conditions) are above the permitted values.

The technical and technological indicators are contained within Group PK 2. They cover issues related to the solutions of transportation of necessary equipment and facilities (especially larger dimensions), then transportation of input raw materials and consumables and output products (electricity and heat, process steam, by-products, such as slag and fly ash, etc.). The activities of technical and technological analysis are considered through two basic aspects: technological and technical, with the technical aspects covering other related areas that have been discussed earlier, and especially those that influence the development of the project from the legislative side. Based on a series of previous analyzes, research and tests, it is necessary to make a selection of their parameters for evaluation. Technology issues during the project preparation phase can be addressed in the selection of technology, preparation of technological documentation, selection of technological equipment and production plan. Technology analysis also implies continuous concern for technological advancement as a whole, so the selection criteria for technology are many and industry-specific, but special attention should be paid to whether it is standard technology, new technology developed and applied, or new technology that has been developed but not yet implemented. Based on the selected technology, technological conditions and data from the technological documentation, technical solutions are developed and adopted, generally referring to a building with associated installations, infrastructure and technical equipment, which together enables the functioning of technological equipment. By the term technical aspects, we also mean those areas that directly condition the development of technical solutions, that is, technical documentation, such as problems of previous research and testing, location conditions, legal and 
International Journal of Mathematical, Engineering and Management Sciences

Vol. 6, No. 1, 118-165, 2021

https://doi.org/10.33889/IJMEMS.2021.6.1.009

property relations, environmental impact of the project, and more. With more complex investment ventures, there may be a need to build more facilities, so in these cases, for the sake of clarity, the data can be grouped e.g., as follows: major production facilities, ancillary manufacturing facilities, general purpose facilities, infrastructure facilities and environmental facilities. With regard to waste storage, the basic location factors that are generally applicable to any selected waste treatment technology are: transportation costs (these costs are becoming more interesting with respect to fuel prices), labor (where increased processing capacity, complex technological operations and process oversight require more skilled personnel) as well as land. For example, depending on the performance and operating parameters, specific fuel consumption at the threshold of a steam condensing power plant ranges from 9,000 to $10,000 \mathrm{~kJ} / \mathrm{kWh}$ for plants from the $1980 \mathrm{~s}$ to 8,000 to $9,000 \mathrm{~kJ} / \mathrm{kWh}$ for modern high-power steam condensing plants parameters (corresponding to coal consumption from 0.36 to $0.40 \mathrm{~kg} / \mathrm{kWh}$ with a lower thermal power of $\mathrm{H}_{\mathrm{d}}$ of about $25,000 \mathrm{~kJ}$ $/ \mathrm{kg}$. It is similar to the use of fuel oil (fuel oil) amounts to 0.24 to $0.26 \mathrm{~kg} / \mathrm{kWh}$, which should provide about $114 \mathrm{t} / \mathrm{h}$ of coal $\left(\mathrm{H}_{\mathrm{d}}\right.$ about $25,000 \mathrm{~kJ} / \mathrm{kg}$ ) for one $300 \mathrm{MW}$ power plant, or $75 \mathrm{t} / \mathrm{h}$ of heating oil $\left(\mathrm{H}_{\mathrm{d}}\right.$ about 38,000 kJ / kg) Sub-criterion PK 2.1 includes the analysis of transport of inputs and outputs of resources in relation to TPP / NPP (cooling water, HV - high voltage transmission line, coal / gas / fuel oil, technical gases, slag and fly ash, traffic accessibility, construction material, etc.). Coal and gas TPP more favorable are locations where it is possible to realize a flow-through cooling system than those that require the use of cooling towers, with more favorable locations with lower costs for the delivery of cooling water. Similarly, for coal and gas TPPs, locations at shorter distances from the hubs or lines of an existing $\mathrm{HV}(400 \mathrm{kV})$ are more favorable. Coal TPPs are more favorable for those locations where it is possible to deliver the required quantities of coal with as little manipulation as possible (fewer transshipments), less transport costs to the landfills with TPP (depending on the type and length of transport), and less requirements for new infrastructure interventions. For gas TPPs, those locations that are closer to the main or transit gas pipelines and the existing or planned metering reduction stations (IASs) to which it is possible to deliver the required quantities of gas are more favorable. Coal TPPs are more favorable for locations with lower slag and ash transport costs to landfills or users. Also, coal-fired TPPs and gas-fired TPPs are more favorable locations with better traffic accessibility and those sites that reach river waterways of the second or higher class. The value function is formed as

$P K_{2.1}=10-\left(D_{H V}+D_{\text {fuel }}\right) / 10-K_{2.1}$,

where, are with $D_{H V}$ and $D_{\text {fuel }}$ given distances from the location of the transmission line HV (400 $\mathrm{kV}$ ) or the location of the fuel in $\mathrm{km}$, and with the sum of negative points obtained in the following way: zero negative points, in case the conditions on the routes for connecting the input / output are very favorable and very simple; one negative point, when the conditions on the input / output connection lanes are favorable and simple; two negative points, when the conditions on the input / output connection lanes are mediocre and require less investment to deal with them; three negative points, in case the conditions on the input / output connection lanes are complicated and require greater investment to deal with them; four negative points, when the conditions on the input / output connection lanes are very complicated and require significantly higher investment resources to address them.

The second sub-criterion PK 2.2 includes the analysis of meteorological and hydrological aspects from the point of view of the cumulative impact on safety from flooding, as well as the possibility of site exposure to extreme meteorological phenomena and impacts. Thus, coal-fired TPPs and gas- 
International Journal of Mathematical, Engineering and Management Sciences

Vol. 6, No. 1, 118-165, 2021

https://doi.org/10.33889/IJMEMS.2021.6.1.009

fired TPPs are more favorable for locations with a higher degree of safety against floods, as well as unprotected locations where the risk of floods is lower. The value function is given in the form

$P K_{2.2}=10-K_{2.2}$,

where, $K_{2.2}$ represents the sum of negative points obtained as follows: zero negative points, in cases where there are no conditions for flooding and where there is no possibility of exposure of the location to extreme meteorological phenomena and impacts; one negative point, when there are minimal conditions for flooding and when there is a minimal possibility of exposure of the location to extreme meteorological phenomena and impact; two negative points, when there are conditions for flooding and when there is a possibility of exposure of the location to extreme meteorological phenomena and impact; three negative points, when there are significant conditions for flooding and there is a significant possibility of exposure of the location to extreme meteorological phenomena and impact; four negative points, when there are high conditions for flooding and there is a high possibility of exposure of the location to extreme meteorological phenomena and impact.

The sub-criterion designated PK 2.3 includes the analysis of the overall conditions related to geology and seismology (seismotectonics and seismics, engineering geology - soil mechanics and foundation, lithology and geomorphology, non-tectonic activity) locations in areas of lower maximum expected earthquake intensity and in neotectonically less active zones. For coal and gas TPPs, as well as landfill locations, more favorable locations are composed of only one type of rock and locations where no liquidation is expected. The more unfavorable the natural conditions at the site (the higher the slope of the terrain, the surface layer of soil of poorer geomechanical characteristics with less allowable load), the worse the location. The existence of poor seismic conditions and engineering-geological characteristics of the soil discredits a particular location from another, whereby it is advisable for seismic micro-regionalization of the location itself to obtain accurate insight into the seismic characteristics of the site (in the first approach), considerations for placement of a thermal power unit exclude locations in high-risk seismic zones with intense seismic activities, locations on routes of already known active faults or fault zones, as well as locations of inadequate engineering-geological characteristics of the soil). For TPP facilities, because of the size of the plateaus they occupy and the necessary conditions for fundraising or foundation, it is not advisable to locate in areas of slope greater than $5 \%$, on riverbeds of drained rivers, notches, passes, plateaus at higher altitudes in relation to the environment and the like. (all these areas are excluded from consideration for the placement of the thermal power facility). The value function is given in the form

$P K_{2.3}=10-K_{2.3}$,

where, $K_{2.3}$ represents the sum of the negative points obtained as follows: zero negative points, in case the overall conditions related to geology and seismology are extremely favorable; one negative point, when the overall conditions related to geology and seismology are relatively favorable; two negative points, when the overall conditions related to geology and seismology are relatively unfavorable; three negative points, if the overall conditions related to geology and seismology are extremely unfavorable.

The overall rating of the PK 2 sub-criterion is equal to the function 
International Journal of Mathematical, Engineering and Management Sciences

Vol. 6, No. 1, 118-165, 2021

https://doi.org/10.33889/IJMEMS.2021.6.1.009

$P K_{2}=\left(P K_{2.1}+P K_{2.2}+P K_{2.3}\right) / 3$,

where with $P K_{2.1}$ to $P K_{2.3}$ values are obtained on the basis of expressions (8) through (10).

Sub-criterion PK 3 includes the analysis of safety and security indicators (emergencies and incidents), where the exception of emergency means a condition created by an emergency, suddenly caused by a natural or human factor, which creates an immediate threat to life and health of people, property of citizens, or is a significant threat to the environment or cultural and historical heritage in a particular area, which the affected community is not able to remove with its own resources and other resources, but the rehabilitation of the whole country and sometimes the international community is needed to repair them, while an accident or incident is a sudden and the imminent threat to life and health of people in a particular area, which the affected community is able to remedy on its own - by its own strengths and means. Emergencies result from the uncontrolled effects of a number of natural phenomena and are most commonly associated with devastating earthquakes, large rock mass movements (landslides, rock fall), floods, long-term extreme weather events, avalanches, regional fires, and other major natural disasters. Major technical and technological disasters that can result in catastrophe and emergency, are related to accidents at installations for oil and petroleum products, failures in the transportation and storage of chemical and toxic materials, explosive and radioactive materials, large pollution of drinking water sources for settlement supply, large traffic accidents, mine accidents, industrial accidents caused by explosions, radiological, biological and epidemiological and other technical or technological accidents. Emergency situations can also arise as a result of major epidemics of infectious diseases (epizootics and epiphytotics - the occurrence of mass diseases of humans, animals and plants). Unlike the catastrophe category, an accident or incident represents a sudden and imminent threat to the life and health of people in a particular area, which the affected community is able to remedy on its own - by its own forces and means. Over the last few years, most of the former Yugoslavia has been particularly destructive with the effects of earthquakes and associated events (landslides and landslides), followed by major floods (especially during 2014), fires and pollution of the natural environment. It is realistic to expect that in the near future such natural phenomena, as well as technical hazards, arising as a result of the inevitable technological and industrial development of the region, will reappear. Conditions for the delivery of equipment are covered by Sub-criterion PK 3.1. The location should be chosen so that the external transport to the site is as cheap as possible and that the transport routes are as short and fast as possible and with the least risk for their realization. It depends on the characteristics of the equipment and facilities for transportation (physical, valuable, need, etc.), the availability of carriers (location, accessibility of rivers, seas, railways, road networks, etc.), the cost of transport for the speed of movement of goods rather than the means of transport, transport time from the point of loading to the destination, safety of goods (theft, damage and other risks), national regulations (quantity, method of packing, transport time), insurance (special packages, supervision), as well as other elements (unloading ramps, equipment required for loading / unloading, means of transport for oversized equipment, etc.). The value function is a measure of the possible risks associated with the delivery conditions of the equipment (environmental conditions - visibility, navigation features, waves, tides, etc., communication conditions - visibility constraints, relief, size, buoyancy, etc., traffic conditions - amount of commercial traffic, congestion, traffic flows, etc. The value function is formed as follows

$P K_{3.1}=5+K_{3.1}$, 
International Journal of Mathematical, Engineering and Management Sciences

Vol. 6, No. 1, 118-165, 2021

https://doi.org/10.33889/IJMEMS.2021.6.1.009

where, $K_{3.1}$ represents the sum of the negative points obtained as follows:

- negative points: 0.2 points per $\mathrm{km}$ of construction of the necessary road infrastructure, in case there is no built access full infrastructure that satisfies the transportation of the required dimensions of the equipment; 1 point in case there is no carrier availability; 1 point for extremely unfavorable transport from the aspect of transport price for the speed of movement of goods; 1 point related to extremely high transport security requirements; 1 point in case of extremely poor other transport conditions,

- positive points: 1 point, in case of positive environmental conditions; 1 point for positive communication conditions; 1 point for positive traffic conditions; 1 point for the existence of each alternative transport.

Somewhat simpler is the PK 3.2 sub-criterion, which covers the analysis of conditions for the delivery of raw materials (primary and auxiliary fuels) and consumables. It is calculated in the same way as the previous sub-criterion PK 3.1

$$
P K_{3.2}=5+K_{3.2},
$$

where, $K_{3.2}$ represents the sum of the negative points obtained as follows:

- negative points: 0.2 points per $\mathrm{km}$ of construction of the necessary road infrastructure, in case there is no full access infrastructure built to satisfy the required dimensions of the equipment; 1 point in case there is no carrier availability; 1 point for extremely unfavorable transport from the aspect of transport price for the speed of movement of goods; 1 point related to extremely high transport security requirements; 1 point in case of extremely poor other transport conditions,

- positive points: 1 point, in case of positive environmental conditions; 1 point for positive communication conditions; 1 point for positive traffic conditions; 1 point for the existence of each alternative transport.

Risk analysis usually involves defining critical variables (with the help of sensitivity, supply and demand analysis, performance / results, human resources, implementation deadlines, financial parameters, etc.), as well as simulation of optimal and worst case scenarios. Sub-criterion PK 3.3 includes the analysis of risk assessment of people permanently or temporarily residing in the immediate vicinity of the TPP or landfill. The source of the risk is the structure and systems of the TPP disposition plan or the landfill itself, as well as the total length of the pipeline for fuel transfer and shipment of slag and ash (if they exist). The value function is calculated as

$$
P K_{3.3}=\left(K_{3.3 .1}+K_{3.3 .2}\right) / 2,
$$

where, the sub-parameters $K_{3.3 .1}$ and $K_{3.3 .2}$ are obtained as follows:

- sub-parameter $K_{3.3 .1}$, which treats the number of persons in the vicinity of a power plant or landfill, obtained as the sum of points $(0.1$ point for every 100 persons at a distance of 1.5 to 5 $\mathrm{km}$ from the site boundary, including temporarily present persons plus 1 point on every 30 persons up to $1.5 \mathrm{~km}$ from the site boundary, including temporarily present persons);

- sub-parameter $K_{3.3 .2}$, which treats the length of the pipeline for fuel transfer or by-product shipment, obtained as the sum of points ( 0 points for pipeline length; points for $\mathrm{m}$ ). 
International Journal of Mathematical, Engineering and Management Sciences

Vol. 6, No. 1, 118-165, 2021

https://doi.org/10.33889/IJMEMS.2021.6.1.009

Sub-criterion PK 3.4 includes proximity and hazard analysis (explosions, fire, traffic accidents of dangerous substances, aircraft crashes, etc.) from the impact of other industrial and other high-risk facilities and facilities located or occurring near the TPP site or landfill). The value function is given in the form

$P K_{3.4}=10-K_{3.4}$,

where, $K_{3.4}$ represents the sum of the negative points obtained as follows: 1 negative point for each hazardous combustible or explosive material system regulated by 40 CFR 68 (US EPA) within 1.5 $\mathrm{km}$ of the site boundary containing flammable and / or explosive materials in quantities above the limit against domestic regulations; 1 negative point to each system with hazardous toxic substance regulated by document 40 CFR 68 (US EPA) within an area of $2 \mathrm{~km}$ from the site boundary containing toxic substances in an amount above the national regulatory limit; 1 negative point to each airport in the area within $3 \mathrm{~km}$ of the location edge.

The overall rating of PK 3 sub-criterion is equal to the function

$P K_{3}=\left(P K_{3.1}+P K_{3.2}+P K_{3.3}+P K_{3.4}\right) / 4$,

where, $P K_{3.1}$ to $P K_{3.4}$ values are obtained from expressions (12) to (15).

Group PK 4 includes an analysis of economic and financial indicators. Socio-economic cost-benefit analysis (cost-benefit analysis) includes a description of cost-benefit analysis units (analysis of investment costs, operating and maintenance costs, reconstruction, revitalization and modernization costs and costs of removing or changing its purpose), social flows analysis (estimation of investment price distortions, wages, fiscal aspects), social benefit analysis (cost / effect cost distortions, social benefits from employment, external benefits, economic net present value (NPV) and cost-effectiveness (CE), as well as additional assessment criteria, from the point of view of presentation of results from the point of view of the general goals of EU standards, increase of GDP, increase of employment, etc. The social assessment of the project determines the usefulness of the project from the point of view of society consisting of different economic entities that can be classified into three groups: employed workers (net personal income + incentives), business owners (up to business essence + residual value at the end of the project) and government (duties, taxes, fees, levies and other fiscal charges). The company can be grouped according to other criteria as well. geographical affiliation, branch of economy-activity, ecology, foreign investments, etc. First, the economic environment of the so-called the wider economic environment in which the project is being implemented, as well as the future development of the project, can significantly affect the financial viability of the project itself, as it includes profit sharing policies, environmental conditions and costs, foreign trade incentives, employment incentives, etc. Second, the societal benefit of the realized investment can be used as an argument for undertaking economic policy measures such as protection against imports at "dumping" prices, obtaining licenses to purchase foreign technology, approving joint ventures with foreigners, and guarantees from the state. In volatile economies, there may be a discrepancy between the official and market exchange rates of foreign currencies (formally but not realistically, the exchange rate is formally fixed in $\mathrm{B} \& \mathrm{H})$, high price inflation with uneven movements across sectors, subsidies, selective tax policies, etc. Qualitative indicators can be based on subjective value judgments or on certain social criteria for project profitability. The economic viability of the project is important, though not always 
International Journal of Mathematical, Engineering and Management Sciences

Vol. 6, No. 1, 118-165, 2021

https://doi.org/10.33889/IJMEMS.2021.6.1.009

crucial, for the social evaluation of the project. The decision on the social viability of the project is made after considering the economic and other social benefits. Valuation of other social and noneconomic benefits can, in economically unstable countries and economies, be emphatically subjective and subject to change even for short periods of time, and the rating and list of priorities is based on the existing economic and infrastructural strength of the company and the adopted economic development plan, such as which is an annual economic policy. Other socially useful indicators can be strongly influenced by political developments, the state of the economy and parties in power, which often results in a more expensive project and diminishes its economic benefits. In each case, the construction of a TPP has significant social benefits, such as: economic development of a wider area of the micro-region and the environment (registration of a new company, new employment, reduction of environmental pollution), increase in the number of employees of all qualifications, increase in budget revenues through payment of taxes and contributions to both the local and wider community (concession fee, regular income and dividend taxes, taxes and contributions to net personal income, etc.), increase in gross domestic product through increased personal consumption (net personal income of employees and subcontractors), increase in public consumption (taxes and contributions) and investment (development of construction and cogeneration systems), rational and efficient use of locally available conventional conventional natural resources (coal, limestone, electricity) and sustainable development with acceptable environmental quality. For a social assessment, it is necessary to convert the current valid price market into a so-called "real" prices (real prices) of resources, which in economic theory are also called "shadow prices", implying perfect competition in the electricity market and other inputs.

Sub-criterion PK 4.1 includes analysis from the aspect of description of units of account for costbenefit analysis (analysis of investment costs, costs of operation and maintenance, costs of reconstruction, revitalization and modernization and costs of removal or change of purpose). The criterion function is formed as

$$
P K_{4.1}=10-K_{4.1},
$$

where, $K_{4.1}$ represents the sum of the negative points obtained as follows:

- zero negative points for coal-fired TPPs with specific construction costs of $\$ 1,000$ to $\$ 1,500$ / $\mathrm{kWe}$ with a construction time of four to six years, with discounted rates of $5 \%$ and $10 \%$, respectively, for the majority of electricity generation costs for most thermal power plants range from 25 to 50 and 35 to $60 \$$ / MWh respectively (investment costs in most cases represent about $50 \%$ of the total amount, operating and maintenance costs range about $15 \%$ and fuel costs about $35 \%$ );

- zero negative points for gas-fired TPPs, which have specific construction costs between $\$ 400$ and $\$ 800 / \mathrm{kWe}$ with a construction period of 2 to 3 years, with a discounted cost of 5 and 10 $\%$, respectively, of the electricity generation costs for most power plants at gas ranges from $\$$ 37 to 60 and $\$ 40$ to 63 / MWh (investment costs represent less than a third of total levies, operating and maintenance costs are less than $10 \%$ in most cases and fuel costs $80 \%$ and up to almost $90 \%$ in some cases. the cost of purchasing gas as fuel represents $73 \%$ of the total leveled cost of electricity production, while investment costs and labor and maintenance costs account for about $20 \%$ and $7 \%$ respectively); 
International Journal of Mathematical, Engineering and Management Sciences

Vol. 6, No. 1, 118-165, 2021

https://doi.org/10.33889/IJMEMS.2021.6.1.009

- one negative point for each energy facility given under a) and b), whose specific construction costs are higher by 10 to $20 \%$ (starting limit given from $\$ 1000$ to $\$ 1500 / \mathrm{kWe}$ for coal-fired TPP, $\$ 400$ to $\$ 800 / \mathrm{kWe}$ for TPP on gas);

- two negative points for each energy facility given under a) and b), whose specific construction costs are higher by 20 to $30 \%$ (baseline given from $\$ 1000$ to $\$ 1500 / \mathrm{kWe}$ for coal-fired TPP, or $\$ 400$ to $\$ 800 / \mathrm{kWe}$ for TPP on gas;

- three negative points for each energy facility given under a) and b), whose specific construction costs are higher by 30 to $40 \%$ (starting limit given from $\$ 1000$ to $\$ 1500 / \mathrm{kWe}$ for coal-fired TPP, or $\$ 400$ to $\$ 800 / \mathrm{kWe}$ for TPP on gas.

PK 4.2 includes the analysis of social flows (estimation of investment price distortions, wages, fiscal aspects), with the function of the criterion formed as

$P K_{4.2}=10-K_{4.2}$,

where, $K_{4.2}$ represents the sum of negative points obtained as follows: zero negative points for an extremely favorable rating, one negative point for a favorable rating, two negative points for an unfavorable rating and three negative points for an extremely unfavorable rating.

Sub-criterion PK 4.3 includes social benefit analysis (cost / performance distortion, social benefit from employment, external benefits, economic net present value - NPV and cost-effectiveness $\mathrm{CE})$, with a function of the criterion formed as

$P K_{4.3}=10-K_{4.3}$,

where, $K_{4.3}$ represents the sum of negative points obtained as follows: zero negative points for an extremely favorable rating, one negative point for a favorable rating, two negative points for an unfavorable rating and three negative points for an extremely unfavorable rating.

Sub-criterion PK 4.4 includes the analysis of additional evaluation criteria from the aspect of presentation of results from the point of view of general goals (EU standards, GDP increases, employment increase, etc.), with the function of the criteria formed as

$P K_{4.4}=10-K_{4.4}$,

where, $K_{4.4}$ represents the sum of negative points obtained as follows: zero negative points for an extremely favorable rating, one negative point for a favorable rating, two negative points for an unfavorable rating and three negative points for an extremely unfavorable rating.

Sub-criterion PK 4.5 includes the analysis of the possibility of constructing cogeneration / hybrid plants as well as other compatible facilities. The capacity of thermal power plants and industrial power plants is based on the planned heat load, which is relevant for the choice of steam generators and turbo-generator units. The main task of these power plants is to supply thermal consumers, whereby the combustion of the same fuel generates both electricity (cogeneration and electricity). In this case, the amount of electricity is a direct function of the production of thermal energy during the winter mode of operation, and any surplus electricity produced is transmitted to the electricity system, the lack of electricity is taken over from the external power system. For combined heat and 
International Journal of Mathematical, Engineering and Management Sciences

Vol. 6, No. 1, 118-165, 2021

https://doi.org/10.33889/IJMEMS.2021.6.1.009

power plants, the total leveled costs of electricity production depend on the use and value of the co-product, i.e., heat, and thus are very specific to the site of construction. At a discount rate of 5 $\%$ and $10 \%$, however, the leveling costs of electricity production range from $\$ 25$ to 65 and $\$ 30$ to 70 / MWh for most cogeneration plants. Elements of economic and financial feasibility represent an important indicator for potential users of hybrid systems when making their final decision regarding investments in these systems. At the same time, the requirement for substantial initial investment funds is sometimes an insurmountable obstacle for the more numerous use of such systems, which is why system optimization is a prerequisite for achieving the financial viability of this system. Proper selection of energy system components in terms of availability and use, installed capacity and capacity, implies meeting the energy needs of consumers by using available conventional (steam, gas) and renewable energy sources (combination with a conventional energy facility). The criterion function is formed as

$$
P K_{4.5}=1+K_{4.5},
$$

where, $K_{4.5}$ represents the sum of positive points obtained as follows: five points for cases where there are excellent possibilities for realization of cogeneration / hybrid systems without any problems, two points for cases where there are possibilities for realization of cogeneration / hybrid systems with less problem and one point for cases where there are possibilities for realization of cogeneration / hybrid systems with significant problems.

The overall rating of PK 4 sub-criterion is equal to the function

$$
P K_{4}=\left(P K_{4.1}+P K_{4.2}+P K_{4.3}+P K_{4.4}+P K_{4.5}\right) / 5,
$$

where, $P K_{4.1}$ to $P K_{4.5}$ values are obtained on the basis of expressions (17) to (21).

The PK 5 criteria group covers environmental aspects and sustainable development. During the construction of a thermal power plant and subsequent exploitation, characteristic influences on the following environmental parameters can occur: air quality, water quality, soil quality, noise level, vibration and radiation intensity, flora and fauna quality, population health, meteorological parameters and climatic characteristics, quality ecosystems, population, concentration and migration of the population, quality of land use and use (built and undeveloped areas, use of agricultural land), natural assets of special value, cultural property, material assets including cultural - historical and archeological heritage, as well as quality of landscape features of the area. Environmental impacts during the construction and operation of the plant are unavoidable, and vary in type, intensity and duration. Thus, during construction, impacts (usually temporary) occur as a result of the construction of the facility and associated facilities, as a result of the very presence and operation of humans and machines, as well as the technology and organization of construction. As a rule, negative impacts result from the excavation, deposition, transport and installation of large quantities of building materials, as well as all activities related to the permanent or temporary occupation of space. Environmental impacts that occur during exploitation are the result of the exploitation and maintenance of a thermal power plant in a specific space. They are generally of a lasting nature with a tendency for spatial and temporal increase of influence, so it is necessary to reveal their existence and nature in a timely manner. The implementation of the environmental impact analysis is prescribed by legal legislation, with the aim of monitoring and implementing adequate measures and activities to reduce or neutralize the negative environmental impacts. In the 
International Journal of Mathematical, Engineering and Management Sciences

Vol. 6, No. 1, 118-165, 2021

https://doi.org/10.33889/IJMEMS.2021.6.1.009

earlier periods related to the end of the last century, the environmental impact and the comparison of the technologies used were expressed in a qualitative description (small, medium, large), whereas at the beginning of this century the need to quantify the impact was demonstrated and a method of weighting factors was developed. Each of the pollutants, depending on the degree of harmfulness, is associated with an appropriate relative amount, and with each technology is assigned a specific set of pollutants, on the basis of whose relative harmfulness is determined by the relative impact on the environment of a particular technology. As the determination of the relative harmfulness of pollutants involves a fair dose of subjectivity, there is a high likelihood of certain doubts in the final result, which ultimately does not diminish the possibility of their application in comparative energy technology analysis or in the cost-effectiveness analysis of environmental measures. In order to satisfy the enacted standards related to environmental protection, significant investments are needed in the measures of its protection, which are reflected in the price of electricity borne by the end consumer. There are other ways to include external costs in decision making, such as penalizing or penalizing and monetizing emissions, i.e., the attachment of certain penalty factors in the first or monetary value to each discharged ton of pollutant in the second case. Recently, numerous studies have been made in which environmental impacts are sought to be quantified and damages are expressed in money, but there is still no generally agreed agreement on the method of evaluation. The incorporation of external costs into the market price of electricity ("internalization") has not yet been widely applied in practice.

Visual impact and landscape impact are the elements traced by the first sub-criterion (group PK 5.1), which analyzes the effects of locating a TPP or landfill on visual changes and influencing the landscape characteristics of a site before locating these objects (lack of site occupancy). The comparative analyzes conducted so far show that visual changes in the landscape are adversely affected by particularly significant changes in the geometry of the space, the high density of differences in the landscape environment, the distortion of color and texture, the deterioration of autochthony, and the introduction of new materials that cannot be adapted to existing ones. For these reasons, it is necessary to consider all the characteristics of the landscape of the site, in order to minimize the damage to both the natural and aesthetic balance of the space. The value of these images can be subjectively evaluated on the basis of the psychological effect they produce (calmness, pleasantness, attraction, desire to repeat the experience, i.e., indifference, aversion, etc.) (Ogrin, 1988). Objective criteria are based on design characteristics (Laurie, 1976), such as the closed or open space, the view of space (the existence of elevations and visual penetrations), the measurability of distance (the existence of plans, screens, etc.), finding the space and reading it (existence of landmarks), flush with the overall image (absence of contrast and foreign). When selecting a site for TPP and landfill, it is necessary to individually analyze and evaluate the relief change, the slope change, the altitude and surface indentation change, the rhythm of the landscape changes, the damage to the edges of natural ecosystems (e.g., forests), the violation of the integrity of the landscape image, the disturbance of the immediate natural environment, the frequency of changes of artificial, built slopes and notches with natural ones. The degree of negative visual change depends on the possibility of restoring natural relationships and new stability, e.g., additional measures and interventions (afforestation). The degree of change is expressed in points: 0 (slight changes),+ (significant changes) and - (complete changes). It is not difficult to see that the analyzes of the existing situation and the proposed variants so far show that all variants will endanger the landscape image, but to a different degree. The value function is formed as follows

$$
P K_{5.1}=10-K_{5.1}
$$


International Journal of Mathematical, Engineering and Management Sciences

Vol. 6, No. 1, 118-165, 2021

https://doi.org/10.33889/IJMEMS.2021.6.1.009

where, $K_{5.1}$ represents the sum of positive or negative points obtained as follows: two negative points for each populated area with more than 200 inhabitants within a $3 \mathrm{~km}$ radius from which TPP facilities or landfills are visible, one negative point for each populated area with 20 to 200 inhabitants and each area for catering, tourist or residential-tourist purposes within $2 \mathrm{~km}$ from which TPP objects or landfills are visible, one negative point for each lookout or main road in the area up to $2 \mathrm{~km}$ from where they have sucked the main road within $2 \mathrm{~km}$ with which are visible TPP facilities or landfills, two negative points if the landscape vulnerability can be assessed as significant, one negative point if the landscape vulnerability can be assessed as moderate, one positive point if there are similar industrial sites within $3 \mathrm{~km}$ of the site. plants or outbuildings with similar visual impact, two positive points if the location is located in an already constructed or planned industrial zone.

Sub-criterion PK 5.2 includes the analysis of the biological-ecological sensitivity of the site and its immediate environment, and includes the evaluation of other biological-ecological characteristics of the TPP site or landfill and its environment, which may jeopardize the operation and exploitation of these facilities as a whole. Impacts on both terrestrial and aquatic / marine life communities are considered. The value function is formed by the following equation

$P K_{5.2}=10-K_{5.2}$,

where, $K_{5.2}$ represents the sum of negative points obtained as follows: two negative points if the site is located outside an already constructed or planned industrial zone, one negative point if the location is within the proposal covered by the community spatial plan, one negative point if the location is within a rare and endangered habitat type.

Sub-criterion PK 5.3 includes environmental protection in terms of site deficiencies in relation to nature and cultural heritage, ecological and biological characteristics, radiological aspects, water quality, soil condition, especially chemical aggression. This deficiency is most often reflected in its capture of the area or in the vicinity of other protected areas or areas with special ecological values, which are not covered by the elimination criterion EC 6. Rich cultural, historical and natural heritage, understanding the importance of protecting cultural and natural heritage with particular attention he approaches the valorization and revaluation of all that is valuable in space, what is important for its identity and what could be in the function of economic progress. The value function is formed by the following equation

$$
P K_{5.3}=10-K_{5.3}
$$

where, $K_{5.3}$ represents the sum of negative points obtained as follows: two negative points in case the area of a potential TPP site or waste landfill is located in: the area of a special reserve of local importance, the area proposed by the spatial plan for protection in the category of significant landscape of local importance and the area classified by the spatial plan as an area of protective or special purpose forest, one negative point if the areas of cultural and historical heritage are recorded in the spatial plan of the potential TPP or waste landfill, one negative point for each of the above contents contained in $1.5 \mathrm{~km}$ in diameter from the center of the potential of the TPP site or the landfill. 
International Journal of Mathematical, Engineering and Management Sciences

Vol. 6, No. 1, 118-165, 2021

https://doi.org/10.33889/IJMEMS.2021.6.1.009

The overall score of the PK 5 sub-criterion is equal to the function

$P K_{5}=\left(P K_{5.1}+P K_{5.2}+P K_{5.3}\right) / 3$,

where, $P K_{5.1}$ to $P K_{5.3}$ values are obtained on the basis of expressions (23) through (25).

Group PK 6 includes the analysis of specific indicators from the perspective of the integration of TPPs or landfills into sustainable spatial development, with given priorities, but usually without action plans, which implies harmonized use of resources, harmonized investment, harmonized technical development, as well as harmonized institutional changes necessary for realization of the set goals of the use of natural resources from the aspect of sustainable development. So, sustainable development is about maintaining a balance between using, saving and rebuilding all our resources and understanding that the generations to come will depend heavily on our operations, with resource exploitation, investment management, technological development direction and institutional change having to fit into the future and present development needs. Sustainable development is a concept that integrates economic success (employment, wages, investments, trade, innovation, entrepreneurship, etc.), environmental quality (water, air, land quality, efficient and rational use of energy, energy resources and their renewability) and social responsibility (combating poverty, creating productive employment of people, promoting social unification through resolved issues of health, education, housing, crime prevention, etc.). Sustainable development means balance. The concept of sustainable development requires the conservation of natural resources; greater equity in the allocation of resources and wealth; introduction and application of new technologies; distinguishing between growth and development concepts; abandoning activities that could jeopardize the interests of future generations; accepting sustainable development as a philosophical approach and pragmatic action. For this reason, the spatial planning strategy and program proposes specific criteria for the evaluation of individual sites for energy objects: preservation of the value of space for priority activities of the area, possible solutions of more environmentally friendly energy products, avoidance of additional load on already burdened areas, primary elimination of conflicts and harmonization of interests of protection of natural heritage and landscapes with the necessary valorization of landscapes and relevant ecological components, the advantage of locating is the devastated spaces and spaces without other activities, which by the construction of energy facilities will remedy the situation and create conditions for economic activity. The first sub-criterion PK 6.1 includes analysis of conservation of space value for priority activities of the area, implies steady economic growth, which, in addition to economic efficiency and technological advancement, greater participation of cleaner technologies and innovation of the whole society and socially responsible business, provides poverty reduction, better use of resources in the long run, improving health conditions and quality of life and reducing pollution levels to the levels that environmental factors can withstand, preventing future pollution and preserving biodiversity. The second sub-criterion PK 6.2 includes an analysis of the possibility of using more environmentally friendly energy. The first task of sustainable energy development in a country is to reduce energy intensity throughout the life cycle from primary energy production through raw material processing and production to the conversion of products and final forms of energy into money and quality of life, which includes the use of waste heat in other industrial plants, as well as in agriculture. The second task is to increase the energy efficiency of fossil fuel use (low energy cogeneration, use of condensing boilers, use of flue gas heat). The third task is a gradual shift to unconventional energy sources (use of biomass, passive use of solar energy, greater use of hydro potential for small hydropower plants). The third sub-criterion PK 6.3 analyzes the 
possibility of using new technologies with higher efficiency (cogeneration, trigeneration, combined steam and gas power generation plants, hybrid systems in combination with renewable sources, etc.), through a harmonized system of technical, economic, and social activities in overall development, using natural and created values in an economical and reasonable way, with the aim of preserving and improving the quality of the environment, including natural habitats and biodiversity, for present and future generations. The fourth sub-criterion PK 6.4 analyzes the retention or reduction of the load of an already loaded area. Environmental protection itself means reducing pollution. This does not mean that future generations will automatically inherit the same amount of natural, social and economic wealth as their predecessors. Through the implementation of measures that support sustainable development, it is possible to maintain the quality of air, water and land for generations to come) and through repeated use and recycling it can be preserved for future generations. In order to realize this, it is necessary to continuously improve the ability to identify effective solutions for sustainable development (education). Sub-criterion PK 6.5 is based on the primary elimination of conflicts and their alignment with the interests of the protection of natural heritage, with the need to valorize the landscape (landscapes) and relevant environmental components over time. Sustainable development is oriented towards developing models that meet the socio-economic needs and interests of citizens in a quality way, while at the same time eliminating or significantly reducing the impacts that pose a threat or damage to the environment and natural resources. Also, sub-criterion PK 6.6 should analyze the possibility of rehabilitation of devastated areas and areas without other activities, while sub-criterion PK 6.7 analyzes the possibility of employment and economic development of depopulation areas.

Due to its specificity, the evaluation of each of the sub-criteria in the PK 6 group will use commonly used valorization in the concept of sustainable development analysis - the weak, moderate and strong sustainability of the sub-criterion under consideration. The value function is the same

$$
P K_{6 . i}=1+K_{6 . i},
$$

where, $K_{6 . i}(i=1,2, \ldots, 7)$ represents the sum of positive points obtained as follows: three points in the case of strong sustainability, which provides for radical changes in society and human relation to nature, with the enhancement of ecological development, two points in the case of moderate sustainability, which is based on the view that places environmental protection as a precondition for economic development and one point for poor sustainability, which implies such disruption of the current state of the environment that is likely to mean less well-being of future generations, and this potential deficiency will need to be compensated through so-called green projects, payment of criminal fees to nature protection funds, etc. The overall score of PK 6 sub-criterion is equal to the function

$$
P K_{6}=\left(P K_{6.1}+P K_{6.2}+P K_{6.3}+P K_{6.4}+P K_{6.5}+P K_{6.6}+P K_{6.7}\right) / 7
$$

where with $P K 6_{5.1}$ to $P K_{6.7}$ values are obtained on the basis of expression (27).

\section{Energy Efficiency and Location of TPP}

The criteria group, designated PK 4, includes the analysis of economic and financial indicators as well as the energy efficiency of the system as a whole. Socio-economic cost-benefit analysis (costbenefit analysis) includes analysis of investment costs, operating and maintenance costs, costs of reconstruction, revitalization and modernization and costs of removing or changing its purpose, then analysis of social flows (estimation of investment price distortions, wages, fiscal aspects), 
International Journal of Mathematical, Engineering and Management Sciences

Vol. 6, No. 1, 118-165, 2021

https://doi.org/10.33889/IJMEMS.2021.6.1.009

social benefits (performance / output cost distortions, social benefits from employment, external benefits, economic Net Present Value (NPV) and Cost-Effectiveness (CE), as well as additional evaluation criteria, in terms of presentation of results from the perspective of the general objectives of EU standards, increasing Gross Domestic Product (GDP), increasing employment, etc. (Milovanović et al., 2011c). When designing an energy efficiency policy, starting from the state of the energy market, it is necessary to define measures that can stimulate market entry and which can accelerate commercialization or increase the penetration of energy efficient products and services in the market (Milovanović et al., 2019). Before incentive policy instruments package definitions need to be thoroughly analyzed, most often including:

- Analysis of direct energy consumption over the last ten years at least (identify historical trends and examine different possible development scenarios),

- Calculation of energy efficiency indicators at the macroeconomic and sectoral level (energy intensity, specific consumption, energy efficiency index, adjusted indicators by climate, diffusion indicators and $\mathrm{CO}_{2}$ indicators,

- Benchmark comparative analysis, analysis with reference countries or analysis with the value of the average for EU-27,

- Setting a national target for improving energy efficiency, both for overall consumption and for each sector separately.

Goals are set for overall energy consumption, as well as for each sector they must be SMART (specific, measurable, ambitious, realistic and achievable in a timely manner). Based on the results of the market analysis, incentive measures are defined and a plausible theory is established on how policy instruments will lead to the achievement of objectives, i.e. the ways in which a particular instrument will lead to economically viable energy efficiency improvements ("ex ante evaluation approach").

\section{Decision Models and Phases for Implementation of the Location Selection Problem}

The difficulty in evaluating the particular environmental and social impacts of the development of new energy facilities and the large number of options for selecting their location requires the application of a multicriteria analysis method, not just the conventional cost-benefit analysis method. In order to ensure a wider range of acceptable alternatives to site selection, it is of particular importance to identify possible criteria (elimination and comparison criteria) that must fundamentally satisfy the elements of sustainable development - economy, environment, energy efficiency and society.

The use of multicriteria decision-making methods should provide assistance to decision-makers when there is a large selection of alternatives to the problem they are solving. In doing so, the process of deciding and choosing the most optimal solution for the design of energy plants is multicriteria type, taking into account a number of factors and interests of different groups and levels of social community (often and mutually opposed), with the participation of more stakeholders in the decision making process (Milovanović et al., 2019). The scope and diversity of energy efficiency projects provide only the basic principles for further development of energy efficiency projects an energy or process plant. Performance indicators for energy efficiency projects are classified into three groups: static, dynamic and non-economic. The question is how to reconcile all these criteria, in terms of different preferences and often conflicting interests. When choosing variant solutions for power plants, the ideal case would be for a situation where all the criteria in the problem could be classified into two categories: profit category, where criteria are maximized, 
where the criterion does not necessarily have to be profit and cost category, where criteria minimize. The ideal solution would be one that allows maximizing all profit and minimizing all cost criteria, which is very difficult to achieve in practice. Since the ideal solution cannot be achieved, the so-called non-dominant solutions (a solution is dominated if there is at least one different solution, which is at least one attribute better than the observed one, provided that it is at least equal in other attributes). The third category consists of the so-called satisfactory solutions, as a reduced subset of possible solutions. Finally, there are desirable, non-dominated solutions that best meet the expectations of the decision maker. In principle, two groups of methods are distinguished - simple non-compensation methods for simpler decision-making and more accurate compensation methods for more complex decision-making, Figure 4.

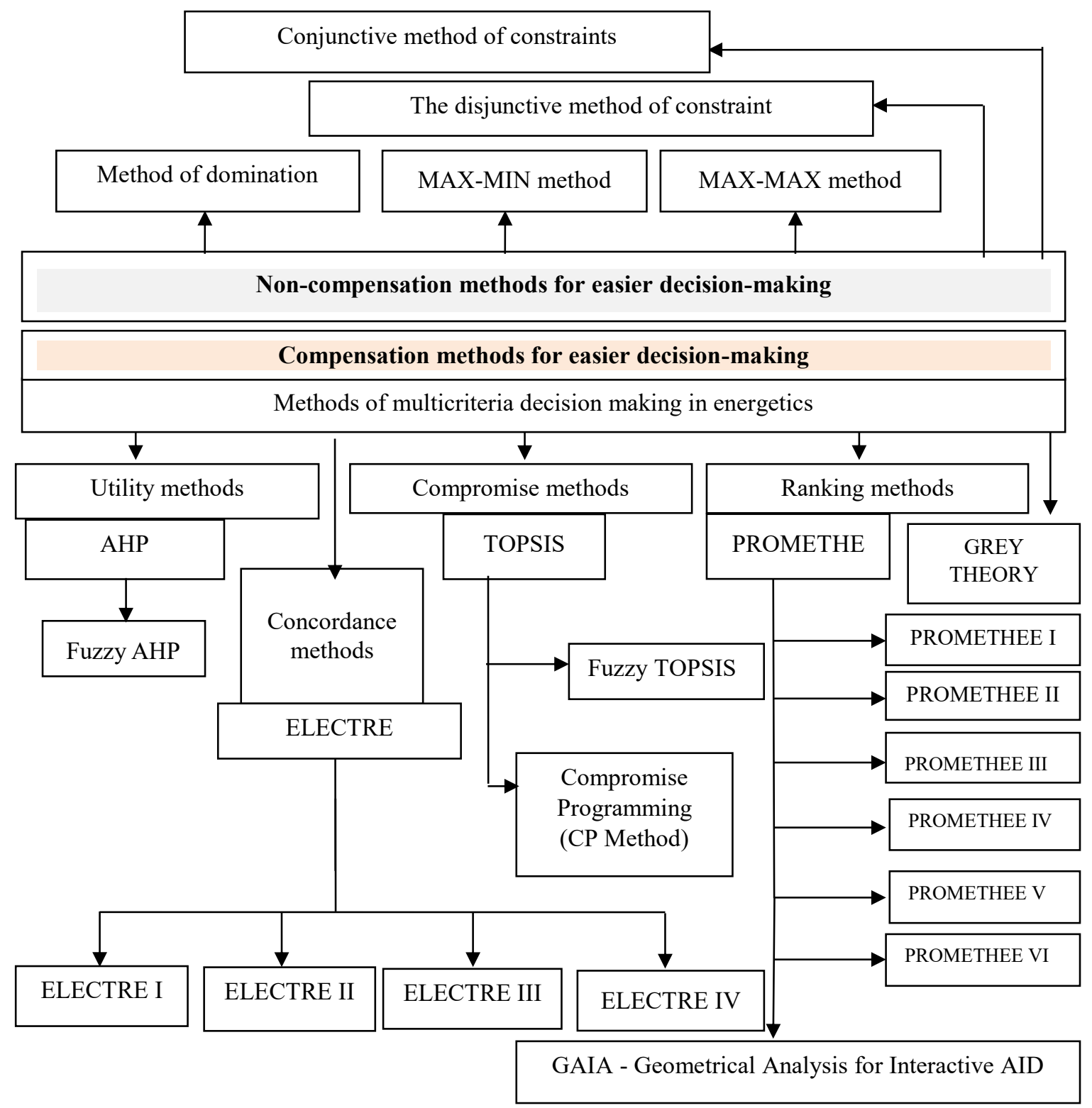

Figure 4. Hierarchical review of decision-making methods in energy (Milovanović et al., 2015). 
International Journal of Mathematical, Engineering and Management Sciences

Vol. 6, No. 1, 118-165, 2021

https://doi.org/10.33889/IJMEMS.2021.6.1.009

Starting from the three most common types of multicriteria tasks, it is possible to distinguish multicriteria optimization (one solution), multicriteria ranking (ranked multiple solutions) and multicriteria separation of a set of good from a set of bad solutions (subset for further problem solving), (Milovanović et al., 2015). In doing so, a finite set of alternatives (decision, action, potential solutions) $A_{i} \in A$ is considered (this number usually does not exceed 4 in practice), where each of the alternatives is described with multiple criteria (attributes, indicators) $P K_{j} \in P K$. For the specific case of TPP site selection, alternatives and criteria are arranged in a matrix format. Each of these criteria is of either maximization (max) or minimization (min) type, while with $x_{i j}$ the value of the $\mathrm{i}$ alternative is given according to the $\mathrm{j}$ criterion and with $W_{j}$ the weight of the criterion (evaluation of its importance). Based on a number of published papers, it can be concluded that AHP is a suitable and highly customizable decision support system for various multi-criteria decision making problems, which on the other hand is implemented as PC platform software with complete multi-criteria technical support decision making. Some uncertainty in decision making may occur when solving some problems, so the so-called fuzzy multicriteria decision making, (Aruldoss et al., 2013). This uncertainty can be caused in two ways: first, when the decision maker is not $100 \%$ certain about making a subjective judgment, called uncertainty about subjective judgment, and second, when information about some criteria is incomplete or not available at all, and called uncertainty due to lack of data or incomplete information. In principle, the solutions of such problems are based on the implementation of ordinary multicriteria decision methods, which are intended for problems defined with a certain uncertainty (fuzzy derivatives of methods such as: fuzzy AHP, fuzzy TOPSIS, etc.), (Aruldoss et al., 2013; Datta et al., 2013).

Gray theory is a method used to study uncertainty, especially when performing mathematical analyzes of technical systems with input uncertain information, especially uncertainty problems, caused by discrete data and incomplete information. The original concept of this method was developed by prof. Ju-Long in (1982). It is used to solve decision problems that are defined with relatively little input information and data, known on a specific scale and unknown on a specific scale (Milovanović et al., 2015). Gray theory deals with high mathematical analysis of systems, which are partly known and partly unknown, and are defined with insufficient data and insufficient knowledge. When the decision-making process is not clear, gray theory examines the interaction analysis between a large number of mutually different and incomplete inputs. In addition to multicriteria decision-making, this method is also used in computer graphics, forecasting, and control of the system as a whole (Milovanović et al., 2015). The gray theory method was used, among other things, in Ozcan's works and in the choice of storage location (Ozcan et al., 2011), and under certain conditions (Aruldoss et al., 2013). it is also applicable in the analysis of the choice of macro and microlocation for complex energy objects.

\subsection{The Dimension of the Problem and the Preliminary Weight of the Evaluation Criteria Groups}

The specific application of multicriteria analysis to the evaluation of the site selection procedure in the framework of pre-investment and investment study analyzes of TPP projects particularly highlights the spatial-geological segment of the analysis (PK 0 and PK 1 criteria), economic and financial analysis (PK 4 criteria), technical and technological segment of analysis (criteria of group PK 2), socio-political segment of analysis (criteria of group PK 6) and environmental-security segment of analysis (criteria of group PK 3 and PK 5). Previously, it is understood that the selected microlocations within the broader macrolocation completely met the elimination criteria in Table 1. These segments of analysis would be evenly assigned $20 \%$ of the value of the sum of weights, 
International Journal of Mathematical, Engineering and Management Sciences

Vol. 6, No. 1, 118-165, 2021

https://doi.org/10.33889/IJMEMS.2021.6.1.009

and within the segment of analysis for the distribution of weights by some criteria, they would be used most often by a survey of expert teams. Some authors pointed to the need to assign more weight to a group of environmental and safety criteria, as well as to the criteria relating to legislation and regulations to meet them. For the realization of the necessary buildings within the energy systems as a whole, Tavares et al. (1999) develops three characteristic main groups of criteria criteria that affect the process of construction of buildings from the TPP layout plan, criteria that speak to the system as a whole, the criterion related to integration systems into the environment, society, politics, culture, etc. According to Tavares (2004), the criteria for comparing imported coal thermal power plant and domestic coal obtained from pit exploitation are grouped according to prevailing characteristics into three groups - technical-technological (A), safety and acceptability of the narrower site (C) and acceptability of the wider site (D). Similarly, the criteria for gas thermal power plants are grouped according to the prevailing characteristics in two groups - technical and technological aspects (A) and location acceptability (B). Ghose (2008) introduces a 21-site method for a new $750 \mathrm{MW}$ thermal power facility: Land Availability, Seismic Stability, Floodplain, Weather, Existing Site Hazards, Existing Land Use, Restricted Air Space, Cultural Resources, Threatened and Endangered Species, Proximity to Public Access Areas, State / Local Environmental Requirements, Proximity to Class I Visibility Areas, Proximity to Specialty Lands Lands, Access to Cooling Water, Fuel Supply Environment, Access to Grid, Rights of Way, Transportation Options Available, Labor and Skills Availability, and cost and Cost and Economic Environment. What is particularly important are the following criteria: method of realization of the cooling system of TPP facilities (Cooling Water Consumption \& Availability), $\mathrm{CO}_{2}$ Transportation and Storage, Land Availability, Labor and Skills Availability and Fuel Supply Consideration.

\subsection{Problem Solving Phases}

The basic stages of problem solving consist of specific modules, which are mutually conditioned. The construction of a concrete model of multicriteria analysis for solving energy problems begins by defining the level to which the model relates, i.e., for the strategic decision-making level, the set of criteria and the generation of actions (alternatives) will certainly have a different procedure than the lower decision levels. Starting from a division into a strategic, tactical and operational level of decision-making (the political level of decision-making is beyond the considered context of the problem), then the strategic level of decision-making can be defined by a macro-territorial approach in defining actions, as well as a time period of 3 to 5 years. Lower levels of decision-making are characterized by a macro and micro-territorial approach (specifically the territory of one region or part thereof, and a municipality or part thereof), that is, periods of less than 3 years and up to several months. The very procedure of applying multicriteria analysis presupposes the realization of certain phases, which include the realization of certain steps, such as: defining the characteristics of the problem, with concrete identification and proper definition of the problem, as the starting and relatively complex phase in the process of obtaining a solution, that is, a set of actions and a set of criteria (defining the dimensions of the problem), reconciling a set of actions and criteria with other stakeholders in the decision-making process (usually some criteria that the stakeholder insists on are added), defining the weights of criteria and types of preference for each criterion, adjusting the weights of the criteria in the iterative the process, defining alternative "scenarios" of processing the criteria weights, giving more weight to a particular group of criteria; development of a mathematical model that reflects a real problem from practice, shaped by specific mapping or translation of a descriptive model into an exact model, as well as model (numerical) processing of problems and presentation of numerical and graphical results of action ranking, choice, elaboration or modification of a method for solving the problem posed, which depends on the model of the problem; solving the model using the method and obtaining a one-sided or accepted one with a 
International Journal of Mathematical, Engineering and Management Sciences

Vol. 6, No. 1, 118-165, 2021

https://doi.org/10.33889/IJMEMS.2021.6.1.009

certain degree of reliability of the results in the expected form; criterion evaluation of the model on the basis of test results, as a measure of consistency of predicted and achieved values, with the most significant criterion being the evaluation of the optimality of the solution through sensitivity analysis, that is, checking the stability of the solution according to the set scenarios weight criteria; implementation of the obtained solution, where theoretical verification of the model accepts the possibility of applying the solution in practice (presentation of results of multicriteria analysis to participants in the decision-making process, numerical processing of additional scenarios or variants of criteria weights, elaboration of results of multicriteria analysis with verbal and graphical interpretation of the obtained ranks).

\subsection{Dimensions of Problems and Preliminary Weighting of Evaluation Criteria}

The weighting of the criteria by which multi-criteria analysis is optimized has different objective and subjective approaches to analysis. One of the subjective frequently used criteria weighting approaches is the criterion-based approach, which converts the rankings into criteria weights, which greatly facilitates the decision-maker's job. In determining individual criterion weights, it is assumed that there is a universal interdependence between the criterion rank and the average criterion weight. In addition, it is understood that this interdependence can be used to combine individual ranks into a set of aggregated (aggregated, group) criteria weights when the ranking of criteria has been performed by multiple experts. A number of authors have considered the advantages and disadvantages of particular methods of determining the weight of criteria (Roberts and Goodwin, 2002). It can be concluded that there is no agreement on the best method for determining the weight of the criteria, and thus on the method of directly determining the "right" set of weights. On the other hand, there is agreement that weights calculated by certain methods are more accurate than weights obtained by direct weighting methods based on an expert's understanding of the significance of the criteria. When calculating the weight of the criteria based on the criterion rank, it is necessary to establish the type of rank-weight function. The selected rank-weight functions, as well as the results of their applications, will be briefly presented below. Several experts may participate in the process of determining the weight of the criteria. It is then necessary to unify the individual ranks (or weights) of the criteria and form unique group weights of the criteria by applying certain methods of pooling the ranks (weights) of the criteria. The paper will present selected methods of combining the individual weights of the criteria, as well as the possibility of applying the methods by developing one example with a brief commentary on the results.

In practice, most experts are usually hired to determine the weight of the criteria, which, based on their personal system of preferences, performs ranking criteria. This raises the problem of forming group values of criterion weights that can be obtained in two ways: by converting individual rankings into weights, and then pooling individual weights or merging individual ranks and converting group rank criteria into group weights of criteria. The formation of group values of criteria weights can be done by applying mathematical methods of unification, applying the methods of social choice theory. Milićević and Župac (2012) based on Elshafei and Alfares (2007) and Alfares and Duffuaa (2008) presented the following mathematical methods of aggregating individual weights (ranks): the method of arithmetic averaging of criteria weights, the method of geometric averaging of criteria weights and the method of geometric criterion rank averaging. The author of this paper considers that it is more correct to use the median of ranks to unify the ranks of the criteria than to geometrically average the ranks. This view is based on the fact that the rankings of the criteria represent values obtained on the ordinal scale, so it is more correct to apply a median of ranks to combine them. 
International Journal of Mathematical, Engineering and Management Sciences

Vol. 6, No. 1, 118-165, 2021

https://doi.org/10.33889/IJMEMS.2021.6.1.009

\subsection{Defining and Adjusting the Weights of the Criteria and Types of Preference for Each Individual Criterion}

The multi-criteria problem of site selection for TPPs contains a number of different, sometimes conflicting, criteria that may be of different importance to the decision maker for a concern project. To assess the degree of importance of the criteria, there are methods dependent on the ability of the expert decision maker or group of experts (judges). In doing so, it is common for the relative importance of criteria to be expressed in terms of priority (the case when criteria are ranked in order of importance) or weight or ponderosity (used to numerically, usually in percentages, express the importance of criteria or to differentiate the relative importance of several criteria within the same priority). In the first case, the post-procedure is implemented in a planned order on the basis of importance, with the next, less important, criterion not at all coming into play, until the more important higher-level criterion is considered. The weights of the criteria reflect the views of decision makers, which have a very high impact on the final decisions for site selection. An important aspect to be considered in determining the weight of the criteria is the subjectivism of the decision maker, which can be somewhat reduced while providing the opportunity for the views of the consulted experts in the field of energy plant design to be given much greater importance than the beginner's when determining the weight of the criteria, which is partly adapted to apply group decision making in the case of a group with different meanings assigned to group participants. Procedures for determining the weight of criteria do not usually form an integral part of multicriteria decision-making methods. Group assessment methods are methods used to determine the importance of criteria in multi-criteria problems, whose main advantage over individual thinking is the broader range of information, expertise and experience in analysis. However, there are also problems such as spending time, the dominance of some authoritative persons, or the ability to persuade a member of the group, which can lead the discussion in a nonessential direction. There are several ways in the literature to determine the weights of criteria, among which we highlight the pairwise comparison procedure, the ranking method, the grading method, successive comparison, the Entropy and Delphi method. Some of the methods used to choose the best alternative are the simple weighting and PROMETHEE methods. Each of these ways has its own advantages, specifics, but maybe some weaknesses. The Simple Additive Weighting method (SAW) is a well-known and widely used multi-attribute decision method, where each criterion (attribute) in that method is weighted directly by a decision maker or one of the weighting methods criterion. The weights of each criterion become the coefficients of variables from the decision matrix in such a way that the total score for each individual alternative is obtained simply by multiplying the data from the decision matrix for each attribute by the weight of that attribute. Adding these multiplications across all attributes gives a final rating of each alternative. The highest-scoring alternative (the highest weighted average) is suggested to the decision maker. The PROMETHEE method was developed with the intention of assisting the decision maker in solving multicriteria decision problems. This method compares and ranks different alternatives simultaneously evaluated on the basis of multiple quantitative or qualitative criteria (attributes). This method compares and ranks different alternatives simultaneously evaluated on the basis of multiple quantitative or qualitative criteria (attributes). For each pair of alternatives $a$ and $b$, a number from the interval $[0,1]$ is determined, where each number closer to the unit means greater acceptability of the alternative $a$ to the decision maker than alternative $b$. The problem is that this eligibility must be measured across multiple criteria at the same time. When we are aware of data related to the values of alternatives by individual criteria, the entropy method can be used to calculate the weights of the criteria. Entropy is an important concept in the social sciences, physics and especially in information theory. It measures the expected content of a message's information. Entropy in information theory represents the criterion for the amount of uncertainty represented by 
International Journal of Mathematical, Engineering and Management Sciences

Vol. 6, No. 1, 118-165, 2021

https://doi.org/10.33889/IJMEMS.2021.6.1.009

the discrete probability distribution $\left(p_{1}, p_{2}, \ldots, p_{n}\right)$ where the "broader" distribution represents a greater amount of uncertainty than the "narrow" one. This measure of uncertainty was defined by Shannon (1948) using the following expression, known as the value distribution entropy ( $\left.p_{1}, p_{2}, \ldots, p_{n}\right)$

$S\left(p_{1}, p_{2}, \ldots, p_{n}\right)=-k \cdot \sum_{j=1}^{n} p_{j} \cdot \ln p_{j}$,

where, $k$ is given a positive constant. In the case where all elements of the distribution $\left(p_{1}, p_{2}, \ldots, p_{n}\right.$ ) are equal, i.e., expression (29) has a maximum value equal to $k \cdot \ln n$, that is, entropy is maximal when the probabilities are equal. Entropy can be used to evaluate the discriminatory power of criteria describing alternatives. The idea of entropy is useful to explore the contrasts between datasets. For example, some criterion does not provide much information useful for comparing alternatives if all alternatives by that criterion have similar ratings. The boundary case is if all values under this criterion are equal and that criterion can then be eliminated from further consideration. In this case, the entropy calculated on the basis of these criteria values will be large and the criterion must be given less weight. Determining the weights of the criteria based on their ranking starts from the need to determine the weight $\mathrm{n}$ of the criteria $A_{j}(j=1,2, \ldots, n)$ based on their ranking by $l$ experts $E_{k}(k=1,2, \ldots, l)$. The procedure is as follows: Each judge (expert) must rank all the criteria in order of importance. The most important criterion is joined by the number $n-1$, the second by the importance of $n-2$, and thus to the least important criterion assigned to 0 . For each criterion $\mathrm{j}$ the sum is calculated of all the rankings given by the assessors to that criterion

$$
R_{j}=\sum_{k=1}^{l} R_{j k},
$$

whereby the $R_{j k}$ number is assigned to the criterion $\mathrm{j}$ on the basis of its ranking by the $k$-th expert. In this case, the criteria weights are calculated as

$W_{j}=R_{j} / \sum_{j=1}^{n} R_{j}$,

the realization of this method is very simple and does not require much time for its realization, and therefore it is often used and very used. It is particularly suitable when the opinion of a large number of persons is relevant for determining the weight of the criteria. Determining the weight of the criteria in the group ratings, each assessor is asked to quantify each criterion. This determines the interval from which the grades will be taken, e.g. $0-10$ or $0-100$. The weights of the individual criteria are then calculated by calculating the values first $W_{j k}=\rho_{j k} / \sum_{j=1}^{n} \rho_{j k}$ and then the values

$W_{j}=\sum_{k=1}^{l} W_{j k} / \sum_{j=1}^{n} \sum_{k=1}^{l} W_{j k}$,

whereby the $\rho_{j k}$ score of the k-th judge for the $j$-th criterion was given, then the weight $W_{j k}$ was calculated for the $j$-th criterion on the basis of the $k$-th judge's rating and the total weight $W_{j}$ for the $j$-th criterion. The magnitudes of $i$ are normalized and their sum is equal to 1 . This method is especially suitable for equalizing the weights of the criteria given by the group members as a percentage. 
International Journal of Mathematical, Engineering and Management Sciences

Vol. 6, No. 1, 118-165, 2021

https://doi.org/10.33889/IJMEMS.2021.6.1.009

In the eigenvector method, the decision maker must judge the relative importance of the two criteria, that is, compare the importance of all possible pairs of criteria. The number of assessments required of the decision maker is equal to the number of combinations without repeating a second class of $\mathrm{n}$ elements, that is, where $\mathrm{n}$ is the number of criteria. The idea on which the eigenvector method was developed starts from the assumption that it is easier for the decision maker to evaluate the relative importance for each pair of criteria than to simultaneously determine the weights or rank all the criteria together. In order to determine the weight of the criteria, it is necessary to evaluate the relative importance of each pair $\left(X_{i}, X_{j}\right)$ in such a way that the decision maker decides one of the following statements: both criteria are equally important, criterion $X_{i}$ is more important than the criteria $X_{j}$, criterion $X_{j}$ is more important than criterion $X_{i}$. The choice of each of these claims entails a corresponding quantification of the weighting of these criteria $W_{i}$ and $W_{j}$, as follows: it is assumed that it is $a_{i j}=W_{i} / W_{j}=1$, or that it is $a_{i j}=W_{i} / W_{j} \succ 1$, or it is taken that it is $a_{i j}=W_{i} / W_{j} \prec 1$. If one of the last two claims is selected, it is possible that the intensity of the preference is the extent to which one criterion is more important than the other expressed by several degrees.

\subsection{Matching Weights of Criteria for Comparison of TPP Micro-Locations}

Starting from the perspectives and needs for the development of TPPs, it is not difficult to conclude that a well-selected site is an important measure of security, and for these reasons it is a very important segment in the implementation of pre-investment project documentation. The macrolocation for each of the coal mines in the observed region is defined by specific strategic documents at the republic or local level. Sometimes these solutions are very expensive and do not follow the trend of development of new technologies and use of new equipment in the field of thermal power and energy as a whole, so it is necessary to additionally evaluate variant solutions according to certain criteria and conditions, which will be applied in the process of comparison and selection of selected microlocations for the implementation of TPP within a pre-selected macro location. These criteria, apart from their differences, can also be contradictory, so in order to evaluate alternatives in multicriteria analysis, it is necessary to have a method to enable their simultaneous processing, taking into account the inherent capabilities of each technological approach and their relative mutual relevance to the criteria. By making the right choice of technical solutions, it is sometimes possible to reduce locations to approximately the same overall environmental impacts, so they can be ranked by the scope of these solutions and the investments required. However, because of the current situation, it is sometimes impossible to fit a given object into the observation space without an unauthorized level of adverse effects. The methods used to compare and rank alternatives based on decision-making input must take into account the advantages of an alternative over others and compare the advantages with its disadvantages. If the criteria are of different importance, their weights should be taken into account. The methods that can be used in this situation are based on certain assumptions that are mathematically characterized. Depending on the weight and complexity of a given model, it is necessary to know the proper mathematical theory to solve it. The procedure for calculating the weights of the criteria and the priorities of the alternatives in the pairwise comparison calculates the priorities of the alternatives and the weights of the criteria, whose values largely satisfy the conditions given by the mutual relations and whose total sum is equal to one. In the first step, a matrix (table) of the ratio of priorities (weight) is formed. The $i$-th row and the $j$-th column of that matrix contain the value of the estimated priority ratio of the alternatives. If estimates of the relative importance of the criteria are given, then this is the value of the ratio of their weights. The calculated values correspond to the weights of the criteria, that is, the priorities of the criteria when evaluating alternatives. This procedure, in the case of consistent 
International Journal of Mathematical, Engineering and Management Sciences

Vol. 6, No. 1, 118-165, 2021

https://doi.org/10.33889/IJMEMS.2021.6.1.009

estimates of the size ratios, gives their exact values. As a control, Saaty's scale helps us evaluate the value of the relation between the weight of the criteria and the importance of the alternatives. Based on the analysis, it can be concluded that according to both concepts (weights and coefficients from the Saaty scale), three criteria are preferred for the evaluation of potential locations for coalfired TPPs: PK4 - economic and financial conditions. PK5 - environmental and sustainable development conditions and PK3 - safety and security indicators (reliability, maintenance and risk), (Milovanović et al., 2011a and 2011b). The result of the previous selection was adopted as optimal and applied in the process of further development of the design solution of TPP Stanari installed capacity of $300 \mathrm{MW}$, Figure 5a. The following criteria are most commonly used for combined steam and gas power plants: on-site environmental conditions, air quality in particular, cost electricity and heat production, socio-economic problems, proximity to available transmission lines, transportation system considerations, fuel availability, water and sewage needs, transportation, real estate availability. According to Delphi and AHP methodology, weight values were obtained for the following 4 comparison criteria, Wu (2012): Nature-related factors $\mathrm{A}-0.232$ (geological parameters - 0.433, water - 0.048, hydrological and geological - 0.520). Technical Factors B - 0.083 (Route Length of Access System Line) 0.049, Access Systems Line Voltage 0.738, Actual Power 0.138, Traffic Conditions 0.078, Economic Factors C - 0.046 (The Total Project Funding) 0.125, Construction Period Interest 0.067, Payback Period 0.071, ROI 0.612, Investment Quotient ( Net Profit Ratio of Capital) 0.125, Radioactivity-Related Safety Parameters 0.639, Basic Legal Requirements 0.632, Reser Contingency Plans 0.229, Population Density and Distribution around the Site 0.082, Impact of External Events on the Nuclear Power Plant 0.05).

The area planned for the construction of the new block of the Ugljevik 3 thermal power plant covers a land area of 30.14 ha, and is located outside the urban area of the settlement Ugljevik. For the given location and realization of the planned contents, property-legal relations, i.e., purchase of land owned by natural persons, were resolved. Part of the plots is the land that represents the ownership share of the TPP Ugljevik. For the purpose of constructing a new block of the Ugljevik 3 thermal power plant, the land for the construction of the residential part, i.e. campus to accommodate work staff to be engaged in the construction of the facility in question, Figure 5. Design solutions for coal exploitation in the Gecko's coal basin should be viewed through valid design solutions for mine surface Gračanica, from the aspect of developing conceptual solutions for the new TPP Gacko 2. In the process of valorization and selection of acceptable potential microlocations for TPP Gacko 2, a similar procedure was applied as for TPP Ugljevik 3. Considering that the macro location and micro location of new energy capacities is defined in the documentation of Mine and TPP Gacko 1, main operating facility (MOF) The second phase of the Gacko TPP is designed in the area adjacent to the MOF of the existing TPP Gacko 1 westbound. The location has been optimized taking into account the climatic, geological, ecological, sociological, technological and other influences on the inhabited places of the Municipality of Gacko and in the previous exploitation of Mining and TPP Gacko 1, proved to be well chosen. All ancillary facilities are located within TPP Gacko 1 near the MOF. For these reasons, backup site variants for the Gacko 2 TPP were not considered, so it was not necessary to carry out additional analysis and ranking of multiple micro locations within the macro location.

\section{Conclusion}

The level of development on which the multicriteria analysis methods are located allows them to be used without any major problems to solve the real problems of choosing variant micro location solutions for a particular thermal power plant. Macro location for each of the coal mines from the observed region is defined by specific strategic documents at the republic or local level. Sometimes 
International Journal of Mathematical, Engineering and Management Sciences

Vol. 6, No. 1, 118-165, 2021

https://doi.org/10.33889/IJMEMS.2021.6.1.009

these solutions are very expensive and do not follow the trend of development of new technologies and use of new equipment in the field of thermal power engineering, so it is necessary to additionally evaluate variant solutions according to certain criteria and conditions, which will be applied in the process of comparison and selection of selected micro locations for TPP implementation in within a pre-selected macro location.
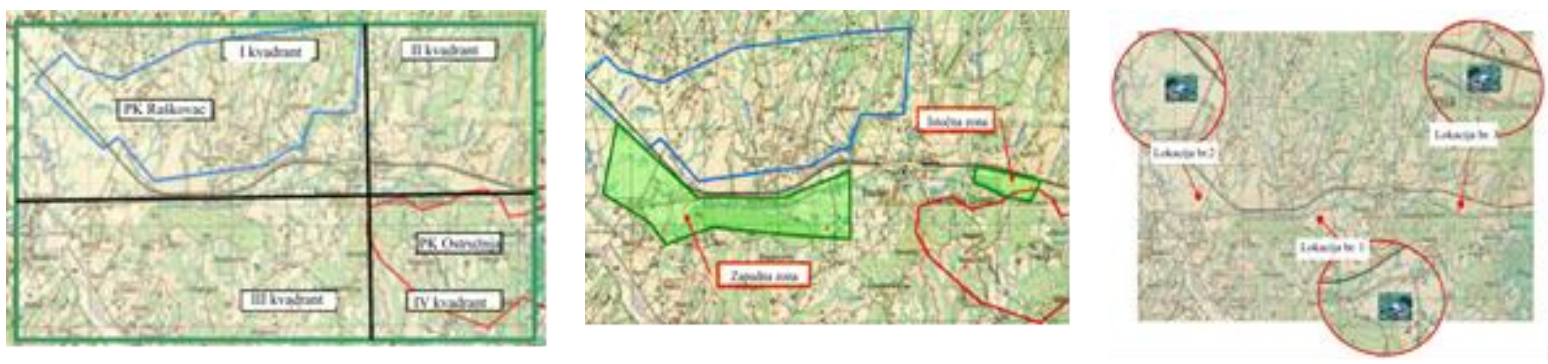

a) TPP Stanari, (Milovanović et al., 2011b)
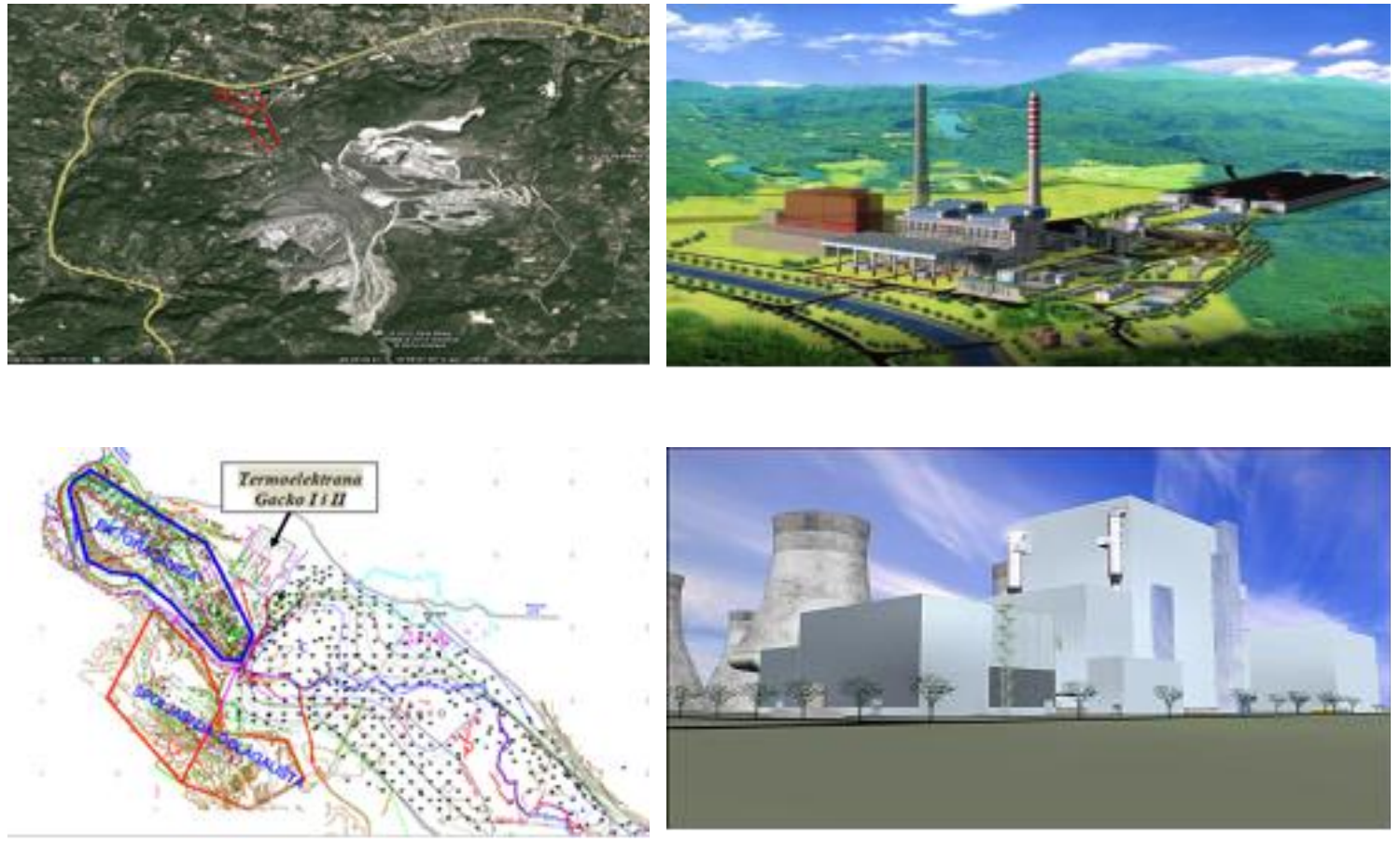

b) TPP Ugljevik 3 and TPP Gacko 2, (Milovanović et al., 2015)

Figure 5. Satellite image and situational overview showing the space provided for the blocks of TPP Stanari, TPP Ugljevik 3 and TPP Gacko 2.

These criteria, apart from their differences, can also be contradictory, so in order to evaluate alternatives in multicriteria analysis, it is necessary to have a method to enable their simultaneous processing, taking into account the inherent capabilities of each technological approach and their relative mutual relevance to the criteria. The process of engineering optimization is a systematic 
search for the optimal solution of a given engineering problem, taking into account the defined optimality criteria, and in the conditions of satisfying the set constraints. Multicriteria analysis methods are being developed in order to enable the systematic involvement of the decision maker (designer) in the process of making optimal choices of variant solutions using computer technology. The main aim of the paper was to analyze the possibilities and development of a mathematical model for the application of the modified multicriteria method for determining priorities between certain alternatives for the realization of the choice of the optimal micro location in predefined frameworks (defined macro location), in a decision situation involving a large number of decision makers of different specialties. The process of choosing a TPP location, until the introduction of preferential locations in the spatial plan of a country or e.g., entities in $\mathrm{B} \& \mathrm{H}$, consists of two phases: the phase of global evaluation of state / entity territory against elimination criteria and the phase of mutual comparison of potential areas identified in this way with the aim of further evaluation and final selection. The aim of the first phase is to identify those wider areas that meet the requirements of all elimination criteria adopted. These potential areas form the basis for future research. Areas that do not meet the requirements of at least one of the elimination criteria are discarded, and the identified potential areas in the second stage of the procedure are subjected to further evaluation by the criteria for their comparison, and detailed comparative analysis using weighting criteria. In this way, smaller areas are allocated within the wider potential areas (macro-locations), so-called potential locations or micro locations (unit areas 0.5 to $20 \mathrm{~km}^{2}$ ). Finally, detailed evaluation of potential sites determines those most optimal or preferred locations. The model was applied to the selection of the optimal micro location for a new thermal power plant with installed capacity of 300 MW (TPP Stanari), as well as the selection of locations on already occupied areas and previously strategically planned so-called. block development (stage development of TPP Gacko 2 and TPP Ugljevik 3). As multicriteria analysis methods are based on significant involvement of decision makers and designers, it is necessary to have a good knowledge of the problem and participation of multiple decision makers of different specialties in order to obtain the optimal order of criteria by which the final micro location is selected for further elaboration of documentation. The level of development on which the multicriteria analysis methods are located and the results obtained from the application of the model allow to achieve good results in choosing the optimal micro location for a particular thermal power plant. Energy efficiency targets are set for overall energy consumption as well as for each sector. They must be SMART, i.e., specific, measurable, ambitious, realistic and achievable in a given time. Based on the results of the market analysis, incentive measures are defined and a plausible theory is established on how policy instruments will lead to the achievement of objectives, i.e. the ways in which a particular instrument will lead to economically viable energy efficiency improvements (ex ante evaluation approach) As multicriteria analysis methods are based on significant involvement of decision makers and designers, a good knowledge of the problem and participation of multiple decision makers of different specialties is necessary in order to obtain the optimal order of criteria according to which the final micro location is chosen for further elaboration of documentation. The methods of multicriteria analysis and the obtained results of model application enable to achieve good results in choosing the optimal micro-location for a particular thermal power plant.

\section{Conflict of Interest}

The authors confirm that there is no conflict of interest to declare for this publication.

\section{Acknowledgments}

This research did not receive any specific grant from funding agencies in the public, commercial, or not-for-profit sectors. The authors sincerely appreciate the editor and reviewers for their time and valuable comments. 
International Journal of Mathematical, Engineering and Management Sciences

Vol. 6, No. 1, 118-165, 2021

https://doi.org/10.33889/IJMEMS.2021.6.1.009

\section{References}

Alfares, H.K., \& Duffuaa, S.O. (2008). Assigning cardinal weights in multicriteria decision making based on ordinal ranking. Journal of Multi-Criteria Decision Analysis, 15(5-6), 125-133.

Aruldoss, M., Lakshmi, T.M., \& Venkatesan, V.P. (2013). A survey on multi criteria decision making methods and its applications. American Journal of Information Systems, 1(1), 31-43.

Bishnoi, L.R., \& Basu, P.C. (2005). Siting of nuclear installations. Nuclear India, 38(7), 8-10.

Brans, J.P., \& Vincke, P. (1985). Note-a preference ranking organisation method: (the promethee method for multiple criteria decision-making). Management Science, 31(6), 647-656.

Chevalier, J., \& Rousseaux, P. (1999). Classification in LCA: building of a coherent family of criteria. The International Journal of Life Cycle Assessment, 4(6), 352.

Datta, S., Samantra, C., Mahapatra, S.S., Mondal, G., Chakraborty, P.S., \& Majumdar, G. (2013). Selection of internet assessment vendor using TOPSIS method in fuzzy environment. International Journal of Business Performance and Supply Chain Modelling, 5(1), 1-27.

Elshafei, M., \& Alfares, H.K. (2007). A dynamic programming algorithm for days-off scheduling with sequence-dependent labor costs. Journal of Scheduling, 11(2), 85-93.

Ghose, S. (2008). Impact of carbon management on plant site selection. Presentation at the West Coast Regional Carbon Sequestration Partnership (WESTCARB) Annual Business Meeting, October 1, 2008, Anchorage, AK. Retrieved from http://www.westcarb.org/Anchorage_pdfs/Ghose_\%20Site Selection.pdf.

Hertwich, E.G., \& Hammitt, J.K. (2001a). A decision-analytic framework for impact assessment. Part I: LCA and decision analysis. The International Journal of Life Cycle Assessment, 6 (1), 5-12.

Hertwich, E.G., Hammitt, J.K. (2001b). Decision-analytic framework for impact assessment. Part II: Midpoints, endpoints and criteria for method development. The International Journal of Life Cycle Assessment, 6(5), 265-272.

Hobbs, B.F., \& Meier, P. (2000). Energy decisions and the environment: a guide to the use of multicriteria methods. Kluwer Academic Publishers, Boston.

IAEA Safety standards series, NS-R-3. Site Evaluation for Nuclear Installations. 2003.

ISO 14040 (2006). Environmental management - life cycle assessment - principles and framework.

ISO 14044 (2006). Environmental management - life cycle assessment - requirements and guidelines management environmental - analyse du cycle de vie - exigences et lignes directrices.

Ju-Long, D. (1982). Control problems of grey systems. Systems \& Control Letters, 1(5), 288-294.

Koopmans, T.C. (1951). An analysis of production as an efficient combination of activities. In: Koopmans, T.C. (ed) Activity Analysis of Production and Allocation. Proceeding of a Conference (pp. 33-97), John Wiley and Sons Inc. London. Energy Information Administration Energy Outlook, DOF/EIA0383(2009).

Kuhn, H.W., \& Tucker, A.W. (1951). Nonlinear programming. In Proceedings of the Second Berkeley Symposium on Mathematical Statistics and Probability (pp. 481-492). University of California Press, Berkeley, California https://projecteuclid.org/euclid.bsmsp/1200500249.

Lee, K., \& Inaba, A. (2004). Life cycle assessment, Best Practices of ISO 14040 Series, APEC.

Milićević, M.R., \& Župac, G.Ž. (2012). Subjective approach to the determination of criteria weights. Vojnotehnički Glasnik, 60(2), 48-70. 
International Journal of Mathematical, Engineering and Management Sciences

Vol. 6, No. 1, 118-165, 2021

https://doi.org/10.33889/IJMEMS.2021.6.1.009

Milovanović, Z., Begić, F., Samardžić, M., Jeremić, D., Dumonjić-Milovanović, S., \& Škundrić, J. (2011a). Optimization of selecting micro location for thermal power plant facility using multi criteria classification: theoretical basis. Termotehnika, 37(1), 29-40.

Milovanović, Z., Begić, F., Samardžić, M., Jeremić, D., Dumonjić-Milovanović, S., \& Škundrić, J. (2011b). Optimization of selecting micro location for TPP Stanari using multi criteria classification. Termotehnika, 37(1), 85-101.

Milovanović, Z., Dumonjić-Milovanović, S., Milašinović, A., \& Knežević, D. (2015). Application of multicriteria decision making for the choice of micro location of new ones thermal power plants (TPP). Thematic Proceedings the Analytical Hierarchical Process - Theoretical Foundations and Applications in Energy, Environmental and Environmental Protection and Education, ALFATEC, Niš, pp. 21-47.

Milovanović, Z., Janičić Milovanović, V., \& Milovanović, S. (2019, November). Management of energy efficiency project at thermal power plants. Proceedings of the Scientific and Expert Symposium Energy Efficiency - ENEF 2019 (pp. 59-66). University of Banja Luka, Faculty of Electrical Engineering, Banja Luka.

Milovanović, Z., Knežević, D., Milašinović, A., \& Dumonjić-Milovanović, S. (2011c). Usage of methods of optimization for selection of constructive conception of facilities of small hydro power plants on previously selected macro locations by method of multicriteria ranking - SHPP Sućeska installed power 2x1.015 MW. Archives for Technical Sciences, 5(1), 9-18.

Ohlopkova, O.A. (2019). Thermal power plant (TPP). Moscow Architectural Institute, Moscow (in Russian).

Özcan, T., Çelebi, N., \& Esnaf, Ş. (2011). Comparative analysis of multi-criteria decision making methodologies and implementation of a warehouse location selection problem. Expert Systems with Applications, 38(8), 9773-9779.

Panigrahi, S. (2014). Fuzzy-TOPSIS for appropriate site selection for establishing a thermal power plant (doctoral dissertation). PhD thesis, National Institute of Technology Rourkela 769008, India.

Roberts, R., \& Goodwin, P. (2002). Weight approximations in multi-attribute decision models. Journal of Multi-Criteria Decision Analysis, 11(6), 291-303.

Roy, B. (1976). From optimisation to multicriteria decision aid: three main operational attitudes. In: Thiriez H., Zionts S. (eds) Multiple Criteria Decision Making. Lecture Notes in Economics and Mathematical Systems (Operations Research), Springer, Berlin, Heidelberg, 1-34.

Saaty, T.L. (1980). The analytic hierarchy process. McGraw-Hill. New York.

Seppälä, J. (2003, June). Life cycle impact assessment based on decision analysis. Helsinki University of Technology, Systems Analysis Laboratory, Research Reports A86.

Shannon, C.E. (1948). A mathematical theory of communication. Bell System Technical Journal, 27(3), 379423.

Swain, D.B. (2014). Supplier selection in risk consideration: a fuzzy based TOPSIS approach. $\mathrm{PhD}$ thesis, National Institute of Technology Rourkela, India.

Tavares, L.V. (1999). Advanced models on project management. Kluwer Academic Publishers, Boston.

Tavares, L.V. (2004). A model to support the search for consensus with conflicting rankings: multitrident. International Transactions in Operational Research, 11(1), 107-115.

Tavares, L.V., Ferreira, J.A., \& Coelho, J.S. (1999). The risk of delay of a project in terms of the morphology of its network. European Journal of Operational Research, 119, 510-537.

Weidema, B.P. (2017). Estimation of the size of error introduced into consequential models by using attributional background datasets. The International Journal of Life Cycle Assessment, 22(8), 1241-1246. 
International Journal of Mathematical, Engineering and Management Sciences

Vol. 6, No. 1, 118-165, 2021

https://doi.org/10.33889/IJMEMS.2021.6.1.009

Weidema, B.P., Pizzol, M., Schmidt, J., \& Thoma, G. (2018). Attributional or consequential life cycle assessment: a matter of social responsibility. Journal of Cleaner Production, 174, 305-314.

Wu, Y. (2012). The study on the site selection of nuclear power plants based on optimized fuzzy comprehensive evaluation. Communications in Information Science and Management Engineering, 2, 35-38. 